University of Tennessee Health Science Center UTHSC Digital Commons

\title{
$12-2011$
}

\section{Nurses Information Appraisal Within the Clinical Setting}

Heather D. Carter-Templeton

University of Tennessee Health Science Center

Follow this and additional works at: https://dc.uthsc.edu/dissertations

Part of the Nursing Commons

\section{Recommended Citation}

Carter-Templeton, Heather D. , "Nurses Information Appraisal Within the Clinical Setting" (2011). Theses and Dissertations (ETD). Paper 37. http://dx.doi.org/10.21007/etd.cghs.2011.0043.

This Dissertation is brought to you for free and open access by the College of Graduate Health Sciences at UTHSC Digital Commons. It has been accepted for inclusion in Theses and Dissertations (ETD) by an authorized administrator of UTHSC Digital Commons. For more information, please contact jwelch30@uthsc.edu. 


\title{
Nurses Information Appraisal Within the Clinical Setting
}

\begin{abstract}
Information appraisal is foundational to information literacy, a necessary skill to support evidence-based practice. Little discussion in nursing literature exists regarding how nurses appraise information. If nurses lack information appraisal skills they cannot safely and effectively apply evidence in practice.

Furthermore, if nurses at all levels are to engage in evidence-based practice, information appraisal in the clinical setting must be understood. The research study used an interpretive description design to define and describe the process of information appraisal in the clinical setting. Participants of this study represented a stratified purposeful sample of 44 registered nurses employed at a regional medical center in west Alabama. Most participants were middle-aged women who were licensed an average of 16 years. Emphasis was placed on how nurses describe and evaluate information as they critically reflect on acquired information in the clinical setting. The research questions were: 1) What is information appraisal within the clinical setting? and 2) How do nurses perform information appraisal in the clinical setting? Participants were assigned to one of seven audio-recorded focus groups of approximately five to seven participants. A semi-structured interview guide assisted in data collection. Participants completed a brief demographic survey. Transcripts from each focus group were coded inductively. Analysis was first done by looking at responses to each question within individual groups, then among groups. ATLAS.ti software was used to aid in data management. Findings suggest that information appraisal is described a number of ways by nurses and an agreed upon definition for the process seems to be lacking among nurses. Based on the descriptions offered by participants information appraisal contains three dimensions: information gathering, information analysis, and information application. In addition, nurses perform information appraisal by way of an unspoken algorithm with two major decision points. First, nurses determine the urgency of the situation. Next, they select the resource of choice based on prior knowledge of available resources, not the content provided by the resources. In most cases, the trusted resource served as a proxy for evaluating the information that was provided by the resource. Research with nurses in the clinical setting is challenging, however, much was gained from discussions with those that had firsthand knowledge of providing direct patient care. Understanding the perceptions of this sample has given insight into how nurses describe and perform information evaluation. Knowledge gained from this study may be used by nurse educators in the academic and clinical setting as they work to deliver relevant information that facilitates providing the highest quality care.
\end{abstract}

\section{Document Type}

Dissertation

Degree Name

Doctor of Philosophy (PhD)

Program

Nursing

Research Advisor

Cynthia K. Russell, PhD, RN

\section{Keywords}

clinical research evidence-based practice focus groups information appraisal information literacy nursing informatics 


\section{Subject Categories}

Medicine and Health Sciences | Nursing 


\title{
NURSES' INFORMATION APPRAISAL WITHIN THE CLINICAL SETTING
}

\author{
A Dissertation \\ Presented for \\ The Graduate Studies Council \\ The University of Tennessee \\ Health Science Center
}

\begin{abstract}
In Partial Fulfillment
Of the Requirements for the Degree

Doctor of Philosophy

From The University of Tennessee
\end{abstract}

By

Heather D. Carter-Templeton

December 2011 
Copyright $(92011$ by Heather D. Carter-Templeton All rights reserved 


\section{DEDICATION}

I dedicate this dissertation to

God, from whom all blessings flow

and to my husband Gary, and my sons Gabe and Noah; you inspire me daily. 


\section{ACKNOWLEDGEMENTS}

I wish to thank the many people who encouraged and supported me throughout my dissertation journey. I wish to express my sincere thanks to my committee members, Dr. Cynthia Russell (chair), Dr. Pam Connor, Dr. Christine Curran, Dr. Leslie McKeon, Dr. Carol Thompson, and Dr. Tami Wyatt. I feel blessed to have had the opportunity to work with each of them. I appreciate the time they have taken with me and the encouragement they offered. Each committee member has helped me in a very specific way. In particular, I would like to thank Dr. Russell for the opportunities she has given me to learn and grow as a doctoral student. I am thankful for the time I have spent under her tutelage.

I would like to thank the nurses who took time from their busy schedules to participate in this study. I would also like to thank DCH Regional Medical Center for hosting this study.

I would also like to thank the Epsilon Omega Chapter of Sigma Theta Tau which helped support this study monetarily with a research award. The chapter's support helped provide incentives for participants in the study.

Further, there were many individuals who supported me both directly and indirectly. I want to thank my colleagues and peers at The University of Tennessee Health Science Center College of Nursing and at The University of Alabama Capstone College of Nursing for their support and encouragement.

On a personal note, I want to thank all of my friends and my entire family. I am so grateful for the love and support you have given me throughout this journey. Specifically, I need to thank my parents for their support, for their belief in me, and for the prayers and encouragement. I must also thank my brother for the laughter that has gotten me through. And to my dear sweet boys, Gary, Gabe, and Noah- I am so thankful for you and simply could not have done this without you. 


\begin{abstract}
Information appraisal is foundational to information literacy, a necessary skill to support evidence-based practice. Little discussion in nursing literature exists regarding how nurses appraise information. If nurses lack information appraisal skills they cannot safely and effectively apply evidence in practice. Furthermore, if nurses at all levels are to engage in evidence-based practice, information appraisal in the clinical setting must be understood. The research study used an interpretive description design to define and describe the process of information appraisal in the clinical setting. Participants of this study represented a stratified purposeful sample of 44 registered nurses employed at a regional medical center in west Alabama. Most participants were middle-aged women who were licensed an average of 16 years. Emphasis was placed on how nurses describe and evaluate information as they critically reflect on acquired information in the clinical setting. The research questions were: 1) What is information appraisal within the clinical setting? and 2) How do nurses perform information appraisal in the clinical setting? Participants were assigned to one of seven audio-recorded focus groups of approximately five to seven participants. A semi-structured interview guide assisted in data collection. Participants completed a brief demographic survey. Transcripts from each focus group were coded inductively. Analysis was first done by looking at responses to each question within individual groups, then among groups. ATLAS.ti software was used to aid in data management. Findings suggest that information appraisal is described a number of ways by nurses and an agreed upon definition for the process seems to be lacking among nurses. Based on the descriptions offered by participants information appraisal contains three dimensions: information gathering, information analysis, and information application. In addition, nurses perform information appraisal by way of an unspoken algorithm with two major decision points. First, nurses determine the urgency of the situation. Next, they select the resource of choice based on prior knowledge of available resources, not the content provided by the resources. In most cases, the trusted resource served as a proxy for evaluating the information that was provided by the resource. Research with nurses in the clinical setting is challenging, however, much was gained from discussions with those that had firsthand knowledge of providing direct patient care. Understanding the perceptions of this sample has given insight into how nurses describe and perform information evaluation. Knowledge gained from this study may be used by nurse educators in the academic and clinical setting as they work to deliver relevant information that facilitates providing the highest quality care.
\end{abstract}




\section{TABLE OF CONTENTS}

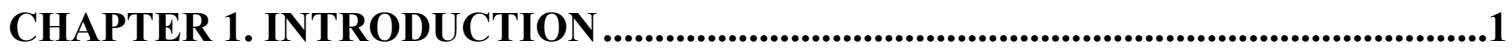

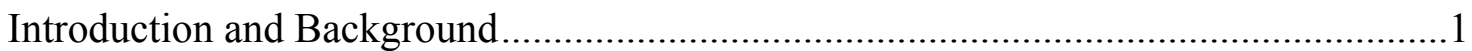

Framework for Study .....................................................................................

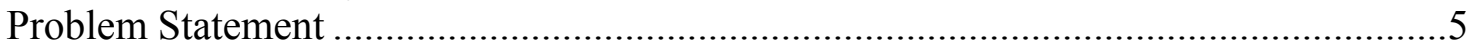

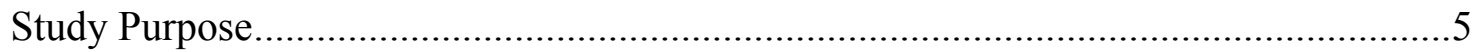

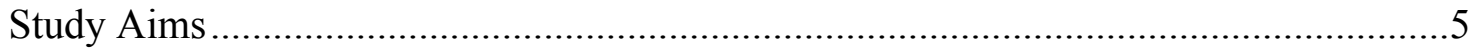

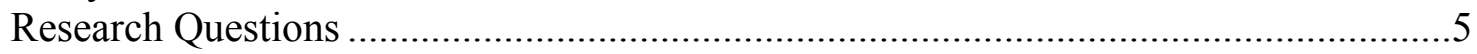

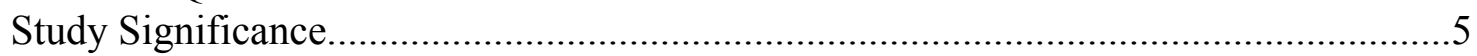

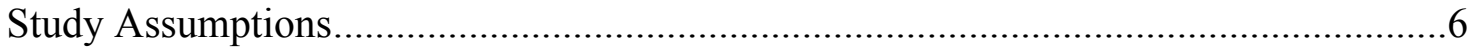

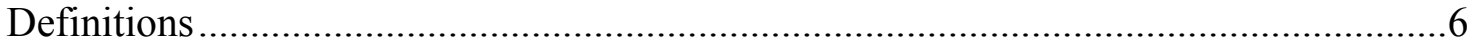

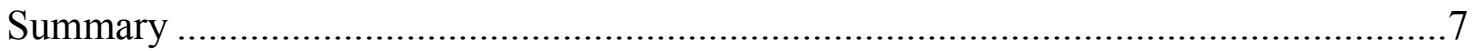

CHAPTER 2. LITERATURE REVIEW ................................................................8

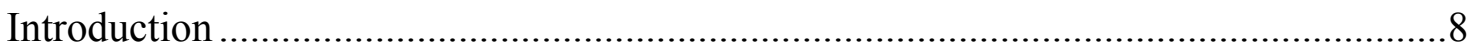

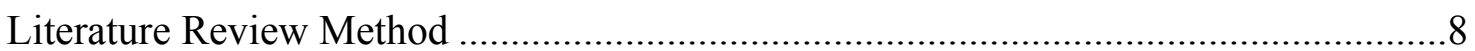

Need for Information Literate Nurses ........................................................................

Information Literacy, Critical Thinking, and Nursing Informatics................................

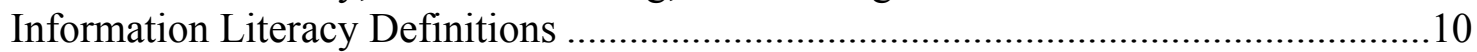

Information Literacy Training Programs within Nursing ........................................11

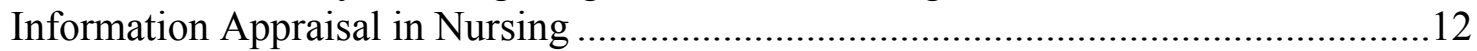

Research-Based Information Appraisal Skills Development..........................................16

Web-Based Information Appraisal Skills Development .............................................18

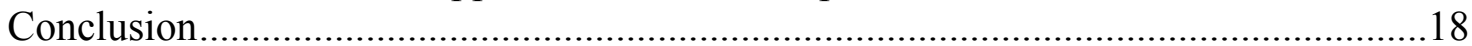

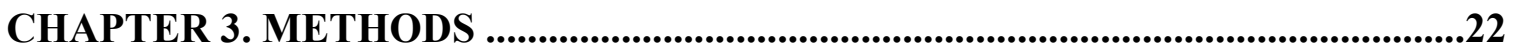

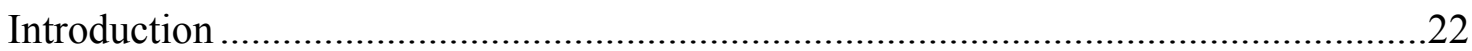

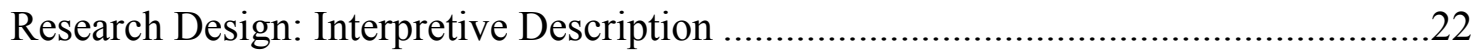

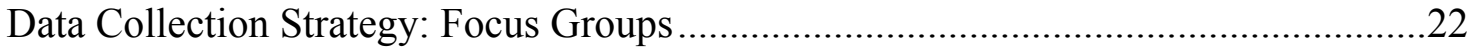

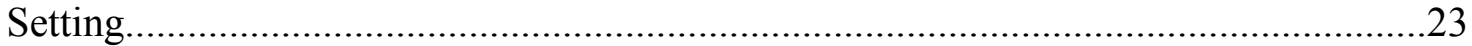

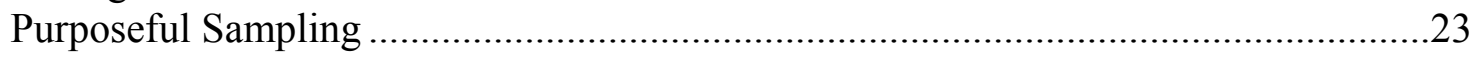

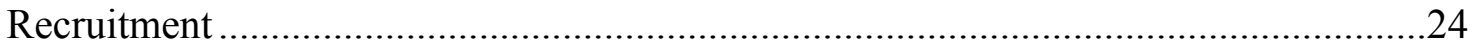

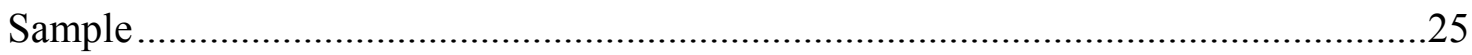

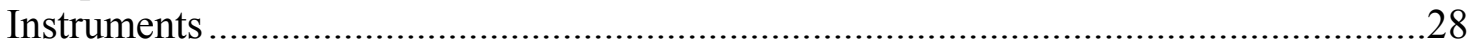

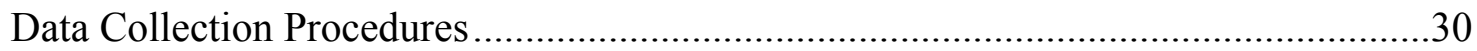

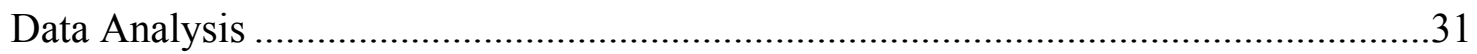

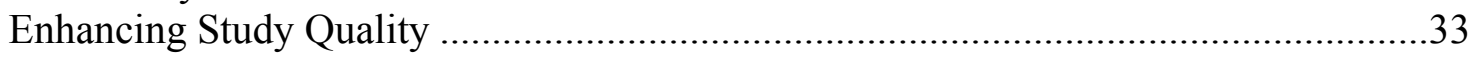

Instrument Development Process ..........................................................................33

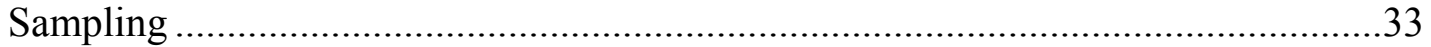

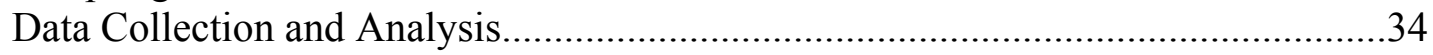

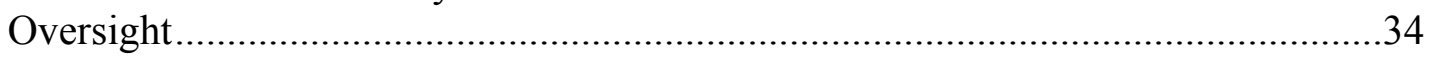

Human Studies Protection ...................................................................................... 


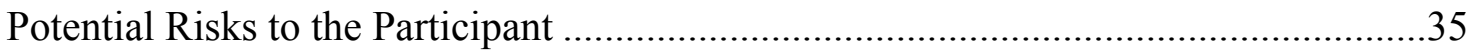

Potential Benefits to the Participant and Society .............................................................35

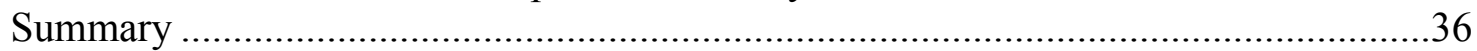

CHAPTER 4. RESULTS.......................................................................................................37

Research Question 1: What Is Information Appraisal in the Clinical Setting? …...........37

Three Dimensions of Information Appraisal ...........................................................37

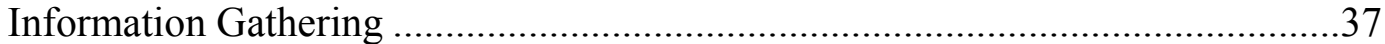

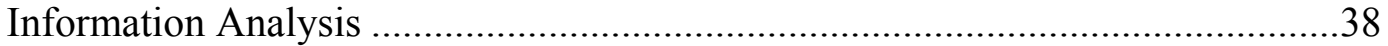

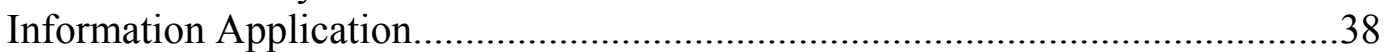

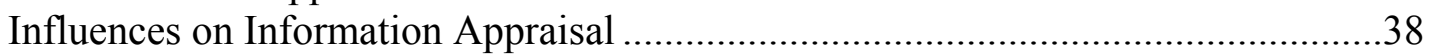

Consistencies in Information Appraisal ..................................................................39

Variability in Participants' Descriptions of Information Appraisal............................39

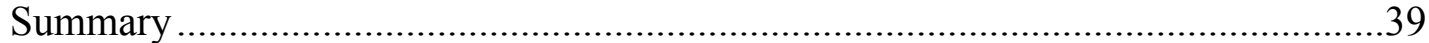

Research Question 2: How Do Nurses Perform Information Appraisal in the

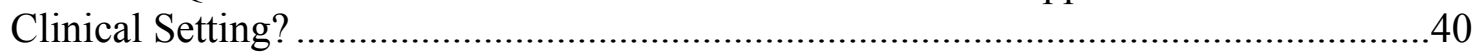

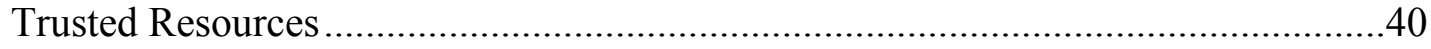

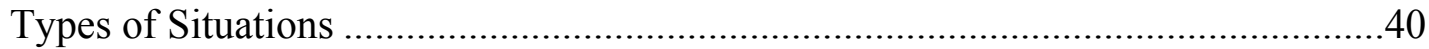

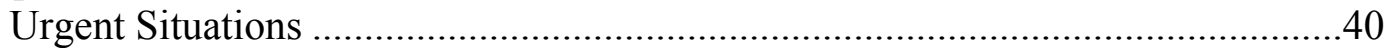

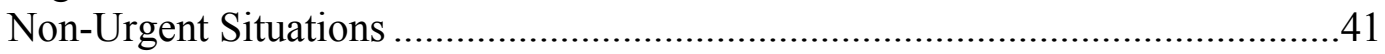

Types of Information Resources ..............................................................................

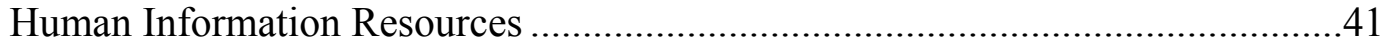

Electronic Information Resources..................................................................43

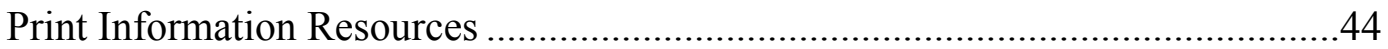

Is It Safe and Logical?: Other Criteria Used to Evaluate Information .......................45

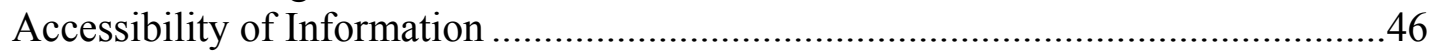

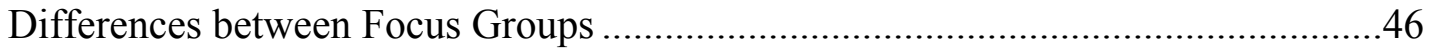

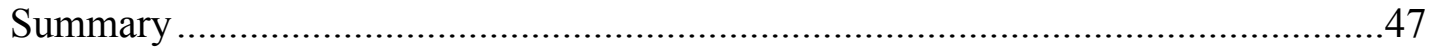

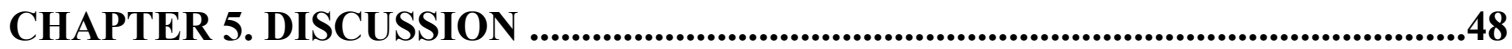

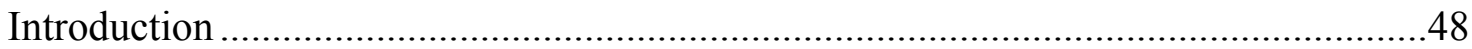

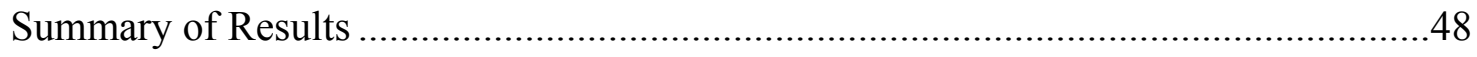

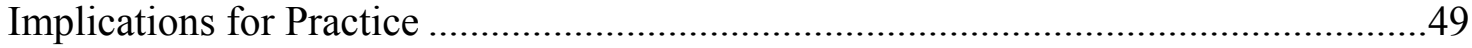

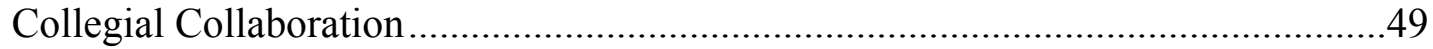

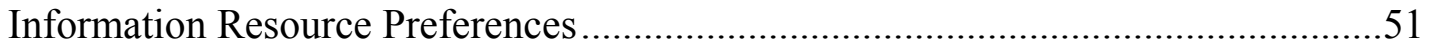

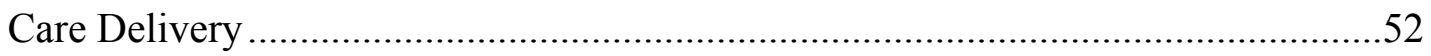

Implications for Nursing Education ......................................................................52

Recommendations for Future Research ............................................................53

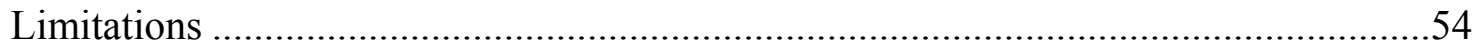

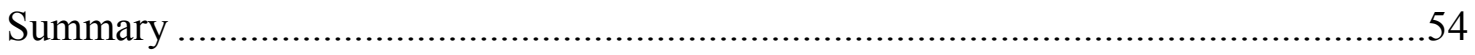

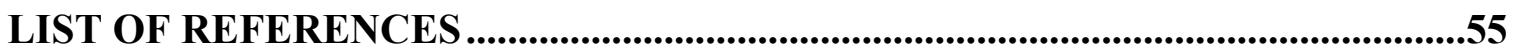

APPENDIX A. RECRUITMENT FLYER .......................................................................62 
APPENDIX B. NURSES' INFORMATION APPRAISAL WITHIN THE

CLINICAL SETTINGS DEMOGRAPHICS SURVEY .....................63

APPENDIX C. SEMI-STRUCTURED FOCUS GROUP INTERVIEW ....................67

APPENDIX D. DEBRIEFING CHECKLIST ...................................................................70

APPENDIX E. FOCUS GROUP PARTICIPANT CONSENT FORM.........................71

APPENDIX F. INSTITUTUTIONAL REVIEW BOARD APPROVAL

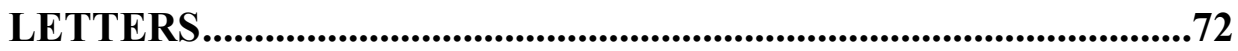

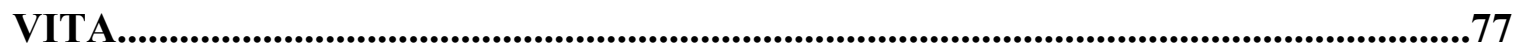




\section{LIST OF TABLES}

Table 2-1. Information Literacy Training Programs in Nursing.................................... 13

Table 2-2. Research-based Information Appraisal Programs in Nursing ....................... 17

Table 2-3. Web-Based Information Appraisal Skills Programs .................................... 19

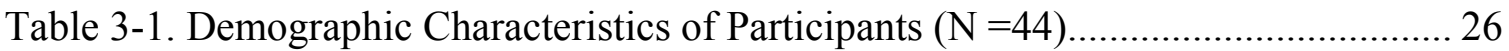

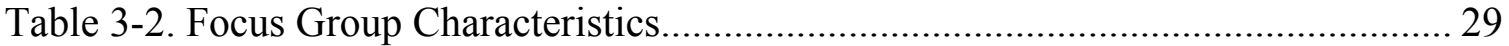




\section{CHAPTER 1. INTRODUCTION}

\section{Introduction and Background}

Nursing has departed from the days when research and research-based findings were left to scholars in academe. The increased emphasis on providing care based on evidence requires nurses to engage in evidence-based practice (EBP) (Phillips et al., 2006) though many nurses are unprepared to do so (Pravikoff, Tanner, \& Pierce, 2005). Nurses must be able to appraise information otherwise they cannot safely and effectively apply evidence in practice (Nolan, 2008; Shorten, Wallace, \& Cookes, 2001).

Information appraisal, which is defined by the author as critically reflecting on acquired knowledge in order to assign value for the purpose of informing action, is a key to nurses providing healthcare based on evidence (Stevens, 2007). In order for nurses to most effectively use evidence in the clinical setting more must be understood about how nurses appraise information. For this reason, the purpose of this dissertation was to define and describe the process of information appraisal by nurses in the clinical setting.

Nurses continuously work with information as part of patient care planning, implementation, and evaluation (Erdley, 2005). They seek information from a variety of sources including colleagues, print, and electronic resources. To further complicate matters information overload exists, with nursing information doubling every five years (Verhey, 1999) and seven million pages of information being added to the World Wide Web everyday (Hall \& Walton, 2004). In an age of ever-growing information resources, nurses at all levels must obtain the skills to find and evaluate information for the purpose of delivering quality nursing care and the advancement of nursing knowledge (Verhey, 1999).

Information appraisal is one phase in the iterative process of information literacy. Information literacy includes recognizing a need for information, searching for, accessing, appraising, and applying information (American Library Association, 2011; LISTEN, 2007). The concept of information literacy has been discussed in the nursing literature still little emphasis is placed on the information appraisal steps (Thompson et al., 2004), the hallmark of evidence-based practice (Stevens, 2007).

The first mention of 'information literacy' in nursing literature dates back to 1996 with Fox, Richter, and White's Pathways to Information Literacy article. More than 15 years later, the nursing discipline continues to struggle with a lack of clarity and misunderstanding of the concept as a whole and the steps that occur within the process. Each phase in the information literacy process is unique in focus and requires a specific skill set of the inquirer. The phases of the information literacy process should be further investigated as a single component to examine expectations and operational definitions. Further, each component should be investigated within the context of nursing to discuss its implications on nursing practice and patient care. For the purposes of this research, only the information appraisal phase was studied in the clinical setting context. 
Criteria used by nurses to evaluate new and various forms of information are often not clearly defined or do not exist. Furthermore, the instruments, such as checklists and scales used to facilitate the appraisal of evidence vary in terms of specificity and may not be applicable in all situations. To further complicate this situation, nurses without graduate degrees usually do not have the skills or knowledge necessary to interpret and use the available instruments (Newhouse et al., 2007). If nurses at all levels are to enact evidence-based practice, more must be understood about what information appraisal is and how nurses appraise information in the clinical setting.

Much discussion exists around the close relationship of EBP, critical thinking, information literacy, and information appraisal, albeit none of these concepts are clearly defined in the nursing literature. EBP is an approach used by nurses that is dependent upon the information literacy and critical thinking skills of nurses. EBP is characterized by using the best available evidence to make clinical decisions in an effort to provide high quality care to patients. Nurses are poised to enact EBP, however, they may not possess the information literacy skills to do so (Pravikoff, Tanner, \& Pierce, 2005). To clarify consider the following: Information literacy is foundational to critical thinking (Breviek, 1991; Verhey, 1999). Critical thinking skills supply necessary skills to support EBP (Newhouse, 2007) and tools considered to belong to the EBP process are actually skills of information appraisal (Jutel, 2008).

\section{Framework for Study}

The framework for this study was developed by the author and is congruent with conceptual models from Englebardt \& Nelson's (2002) Relationship of Data, Information, Knowledge, and Wisdom, Rycroft-Malone et al.'s (2004) Four Sources of Evidence for Patient-Centered, Evidence-Based Care, Ford \& Profetto-McGrath's (1994) Model for Curriculum as Praxis, and synthesizing information literacy research literature. The framework guiding this study presents and illustrates the relationship between multiple concepts and processes working together as information is appraised by nurses within the clinical setting (Figure 1-1).

Nursing is an information based discipline (Graves \& Corcoran, 1989). Nursing informatics integrates nursing science, computer science, and information science. This integration is in an effort to manage data, information, and knowledge in nursing practice (Staggers \& Thompson, 2002). Nursing informatics facilitates and supports the information literacy process with collaborative tools, online access to search engines and databases, and information storage tools. Phases of the information literacy process include: information deficit recognition, information seeking, information retrieval, information appraisal, and information application (American Library Association, 2011; LISTEN, 2007). Actions within each information literacy phases often rely on information technology, research, and critical thinking skills (McGonigle \& Mastrian, 2009) and are often studied within the specialty of nursing informatics.

Recommendations of the American Nurses Association (ANA) call for all nurses to be information literate (American Nurses Association, 2008). Being information 


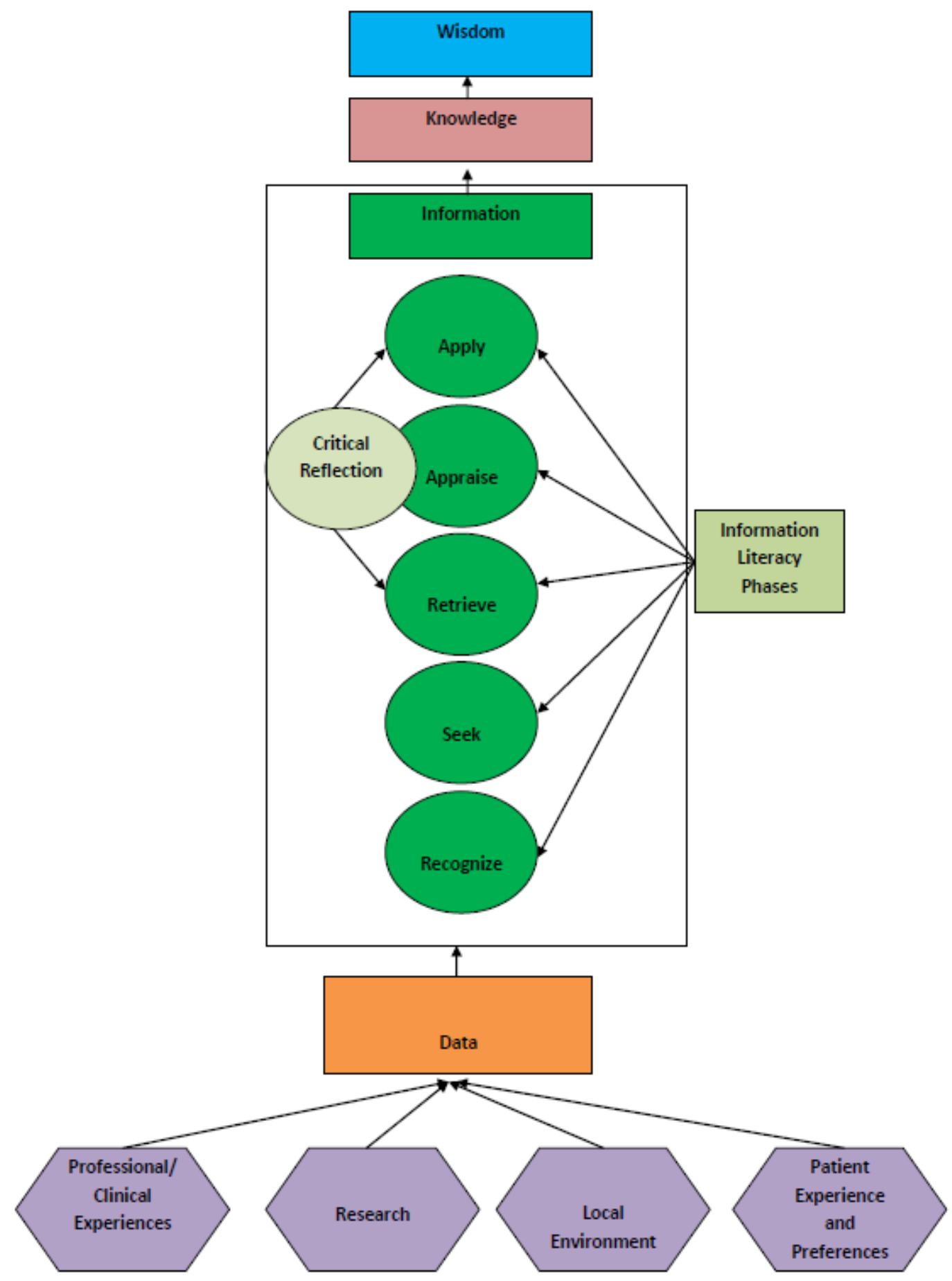

Figure 1-1. Conceptual Model: Nurses' Information Appraisal within the Clinical Setting Model 
literate requires knowing how to clearly define or describe a subject or concept being examined, using appropriate terminology, formulating a strategy used to search for information, using online bibliographic databases, using critical thinking skills to assess information collected for value and suitability to the situation and, as a result, converting information into knowledge (American library Association). The link between information literacy and critical thinking has been documented in the literature (Brevik, 1991; Fox, Richter, \&White, 1996). Critical thinking, like information literacy, involves formulating a precise and clear question, gathering and accessing information, and arriving at reasonable conclusions that can be measured against criteria and standards (Johnson, Lindsay, \& Walter, 2008). Though nursing education has emphasized critical thinking skills, information literacy skills have received little attention (Verhey, 1999) and even less emphasis has been placed on each phase of the information literacy process.

The Model of Nurses' Information Appraisal within the Clinical Setting, is congruent and reflects the works of multiple authors in the areas of evidence-based practice, critical thinking, nursing informatics, and information literacy. In The Model of Nurses' Information Appraisal within the Clinical Setting data are provided from research, professional/clinical experiences, the local environment, and/or patient experiences and preferences (Rycroft-Malone et al., 2004). The information literacy process is then implemented as data transform into information and are placed into context and interpreted. As data transform into information the five step information literacy process is enacted:

- First, a nurse must recognize a need for more information or question existing information. As this point, the construction of the clinical question begins. A common tool used to frame the clinical question is the PICO (patient, intervention, comparison, and outcome) system.

- Next, the information-seeking phase occurs. Using the clinical question, a nurse may use key words or search terms that vary in usefulness in databases or search engines. Or, nurses may simply be able to clearly communicate the clinical question with an expert in the field.

- The third phase is the information retrieval phase. In this phase, the new information gained is stored. It may be received or downloaded and stored in a variety of ways.

- The fourth phase and the focus of this study is the information appraisal phase. During this phase the information gained is critically evaluated in order to assign value for the purpose of informing action (Ford \& Profetto-McGrath, 1994).

- The last phase of the information literacy process is the information application phase. During this phase the information is applied appropriately and safely to the patient care situation. 
The evidence is derived from a variety of sources (primary or secondary). Over time knowledge becomes wisdom, which focuses on the appropriate application of the knowledge. Wisdom can be used in future practice or built on again with new or additional data collected within the clinical setting (Englebardt \& Nelson, 2002).

\section{Problem Statement}

Many nurses experience difficulty in determining quality of resources, credibility, relevance, and accuracy of information due to the amount and variation in available literature (Estabrooks, O’Leary, Ricker, \& Humphrey, 2003; Fox, 1998). If nurses cannot appraise information, they cannot safely and effectively apply evidence in practice (Nolan, 2008). Little discussion in the literature exists regarding how nurses appraise information.

\section{Study Purpose}

The purpose of this qualitative descriptive study was to define and describe the process of information appraisal in the clinical setting. The research focused on nurses' definitions of information appraisal and how nurses appraise information in the clinical setting.

\section{Study Aims}

This study aimed to describe the information appraisal experiences of practicing nurses. Emphasis was placed on how nurses describe the process of information appraisal and how they evaluated information as they reflected on acquired information for the purpose of informing their actions in the clinical setting.

\section{Research Questions}

The following research questions were explored:

- Research Question 1. What is information appraisal in the clinical setting?

- Research Question 2. How do nurses perform information appraisal in the clinical setting?

\section{Study Significance}

Information appraisal is an important phase in the information literacy process and significant to providing care based on evidence (Thompson et al., 2004). However, limited research has been done on the specific topic of information appraisal in the 
nursing discipline. Studies that are available often discuss the entire information literacy process, not information appraisal specifically. The findings from this research are expected to extend nursing knowledge related to the unique phase of information appraisal within the information literacy process in the clinical setting.

\section{Study Assumptions}

The researcher made the following assumptions:

1. Participants were representative of the population being studied.

2. Participants were useful sources of information about themselves and the clinical setting.

3. Participants were able to clearly articulate their perspectives and perceptions.

4. A structured group setting facilitated data collection from participants about perspectives and perceptions related to information appraisal.

\section{Definitions}

The following terms are defined for clarity; the conceptual and operational definitions for these terms are provided in this section.

- Critical thinking was conceptually defined as "problem solving as reflected in the nursing process" (Ford \& Profetto-McGrath, 1994, p. 342).

Operationally, critical thinking was defined as the entire process of acquiring knowledge, critically reflecting and appraising information, and creating an action in response.

- Evidence based practice (EBP) is characterized by the use of the best evidence currently available for clinical decision making, in an effort to deliver the best possible care to patients (Pravikoff, Tanner, \& Pierce, 2005). EBP was conceptually defined as a systematic approach to problem solving used by health care providers. EBP was operationally defined as the action that results from a problem solving approach that considers experiential evidence with research evidence through critical reflection.

- Information was conceptually and operationally defined as data that have been interpreted (Hebda \& Czar, 2009). These data can be found in a variety of forms and sources including but not limited to journal articles, textbooks, websites, and colleagues.

- Information appraisal was conceptually and operationally defined as critically reflecting on acquired knowledge in order to assign value for the 
purpose of informing action. The terms information appraisal, critical appraisal, information synthesis, systematic review, and information evaluation are often used interchangeably in the literature. Each of these terms suggest the process of systematically assessing and interpreting information to be incorporated in nursing practice. For purposes of this study, the term information appraisal was used.

- Information literacy is a developing and emerging process that assists in defining information needs. It is conceptually and operationally defined as a process applied to recognize when new information is needed and to locate, evaluate, and use information effectively (American Library Association, 2011). Each phase in the information literacy process is unique in focus and requires a specific skill set for the person engaging in the process.

\section{Summary}

Chapter 1 introduced the specific problem domain, information appraisal, and described how information appraisal is related to the more general concepts of EBP and information literacy. The chapter describes the study framework which depicts the interconnectedness of different forms of evidence, the information literacy process, and critical thinking. The fact that nurses struggle in determining credibility, relevance, and accuracy of information, as reported in the literature, substantiates the relevance and need to examine this process. Hence, this qualitative study investigated information appraisal in the clinical setting. Finally, definitions pertinent to a foundational understanding of the topic were described from conceptual and operational perspectives. Based on this understanding the next chapter discusses the concept of information appraisal as reported in scientific literature. 


\section{CHAPTER 2. LITERATURE REVIEW}

\section{Introduction}

The purpose of this chapter is to review the literature on information appraisal and to identify areas for theoretical expansion and further research. This review is important because information appraisal is essential to providing evidence-based care (Stevens, 2007). Limited information appraisal abilities have been identified as a barrier to evidence-based practice (Pravikoff, Tanner \& Pierce, 2005).

This chapter provides a review of the literature in order to understand the process of information appraisal and related concepts of information literacy and critical thinking under the nursing informatics metastructures. First, a description of the literature review methods and an introduction to the theoretical context of information appraisal as it supports evidence-based practice (EBP) will be described. Next, the dependence of EBP on information literacy, which is dependent on the ability to appraise information, will be discussed. This chapter will explain why it is necessary to consider information appraisal broadly and generally when defining what it is and how it is performed in the clinical setting.

\section{Literature Review Method}

The question guiding the literature review was: How has information appraisal been discussed and conceptualized in nursing literature? Electronic searches in CINAHL, PubMed/MEDLINE, and the Cochrane Systematic Review Database were conducted. Search terms used in the electronic search included information appraisal or information evaluation, and information literacy to find sources on information literacy and information appraisal. The truncated version of "nurse" (nurs*) was also used in conjunction with the above keywords to maximize the amount of potentially relevant articles to be included in this review. The total number of articles retrieved was 179 , however, many were irrelevant or focused on the related topic of health literacy. The electronic search yielded 25 items appropriate for this chapter. Informatics textbooks were also reviewed for relevant information. Reference citations from articles and texts were manually searched and harvested to locate additional relevant information. In addition, informal channels of communication with experts in the topic area and health science librarians were consulted to help locate literature germane to the topic (Cooper, 1998).

In both the electronic and manual searches, articles were not excluded on the basis of the level of evidence or study quality. In many cases, information about the specific step of information appraisal was discussed within the context of information literacy and/or evidence-based practice (EBP).

Literature was categorized into three groups: information literacy skills development, research-based information appraisal skills development and web-based 
information appraisal skills development. Data from each article were entered into a worksheet for critique. Categories of the critique worksheet included the purpose and research questions, data collection methods, study design, major findings and limitations, sample information, setting, type of nursing program, and major tools used.

\section{Need for Information Literate Nurses}

In nursing, EBP is the identification of the best available evidence to inform decisions leading to quality healthcare care (Young, 2000). EBP provides a rationale for using best practices while disregarding ineffective practices (Prior et al., 2010). In fact, research indicates that healthcare providers who use evidence-based approaches in their patient care delivery experienced improved patient outcomes by $28 \%$ (Heater, Olsen, \& Beck, 1998), experienced higher levels of satisfaction (Dawes, 1996) and institutions benefitted from decreases in patient length of stay and cost. EBP is known throughout the global healthcare community to play a vital role in delivering high quality healthcare and ensuring the best patient outcomes. Unfortunately, care based on evidence is typically not the norm (Melnyk \& Fineout-Overholt, 2010; Pearcey, 1995), which is a problem that has resulted in research on the barriers to delivering evidence-based care (Estabrooks, et al., 2003; Hannes et al., 2007; Pravikoff, et al, 2005; Tannery et al., 2007). A commonly cited barrier is the lack of information literacy skills (Ciliska, 2006; Kohen \& Lehman, 2008; Pravikoff, et al, 2005). It is believed that EBP cannot be applied in the absence of information literacy skills (Tanner, Pierce, \& Pravikoff, 2004).

Literature upholds the use of EBP techniques when incorporating evidence into decisions made in the clinical setting. Many believe that practice based on evidence is now the expected standard of care in nursing (Taylor-Seehafer et al., 2004). However, administering treatments and interventions that are not scientifically based is common (Young, 2000). Between $20 \%$ and $25 \%$ of patients receive unnecessary or harmful treatments, meanwhile it is estimated that $30 \%$ to $40 \%$ of patients do not receive care that is proven effective (Milne, Krishnasamy, Johnston, \& Sanchia, 2007). Ironically, a number of data from hospitals reflect that nursing care is based on evidence (Hebda \& Czar, 2009). Lack of information appraisal has been discussed in the nursing literature as a barrier to delivering evidence-based care (Cheek, Gillham, \& Ballantyne, 2010; Milne et al., 2007; Pravikoff, Tanner, \& Pierce, 2005), and perhaps a contributing factor to these findings.

\section{Information Literacy, Critical Thinking, and Nursing Informatics}

Information literacy, an ambiguous concept (Saranto \& Hovenga, 2004) closely connected with critical thinking (Johnson, Lindsay, \& Walker, 2008), is the process used to recognize when new information is needed and to locate, evaluate, and use information effectively (American Library Association, 2011). Effective information literacy skills influence a wide range of knowledge-based behavior in the healthcare setting. Information literacy is considered a prerequisite to EBP (Shorten, Wallace, \& Crookes, 2002), foundational to being a lifelong learner (American Library Association, 2011) and 
one of the most important skills to be gained through nursing education (Verhey, Levy, \& Schmidt, 1998). Unfortunately, many (if not most) nurses do not possess adequate information literacy skills (Dee \& Stanley, 2005; Pravikoff, Tanner, \& Pierce, 2005). For practice-related questions, nurses are not using the most up-to-date resources, but rather sources of general and less-credible information (Estabrooks et al., 2002; Pravikoff, Tanner, \& Pierce, 2005). Nurses tend to seek information from their colleagues and draw on their past experiences instead of looking to journals and textbooks for information relevant to their clinical practice questions (Estabrooks et al., 2005).

In order to effectively make use of available electronic information sources, nurses must have information literacy skills, which have become an important concept of nursing informatics. Information literacy skills are defined here as the ability to identify a need for information, access, retrieve, appraise, and apply information (American Library Association, 2005).

When nurses possess information literacy skills, the potential exists for improved outcomes at the institutional, nurse, and patient levels. Unfortunately, many (if not most) nurses do not possess adequate information literacy competencies (Dee \& Stanley, 2005). Further, many nurses who use the Internet to access healthcare information have received little to no formal technical training to ensure information is reliable, valid, and from a credible resource. Studies indicate that nurses receive less education related to information technology and information literacy than do most other health care workers (Alpay \& Russell, 2002). As a result of inadequate IT and information literacy competencies, nurses are twice as likely to seek out general and less-credible information as to target information relevant to practice (Estabrooks, O'Leary, Ricker, \& Humphrey, 2002). This may be a result of nurses not being adequately trained to use online information resources (Pravikoff, Tanner, \& Pierce, 2005).

\section{Information Literacy Definitions}

Since the 1970's much has been written about information literacy, mainly within the library sciences discipline. Information literacy is usually understood as being abstract and complex and involves having knowledge of bibliographic databases and the subject matter. Technical skills used to navigate bibliographic databases are complimentary to the knowledge of the discipline being studied (Cheek \& Doskatsch, 1998). A review of 32 definitions of information literacy revealed that most authors use a definition similar to the American Library Association's definition which states that information literacy is a group of abilities used by individuals to recognize when information is needed and to locate, evaluate, and effectively use information (American Library Association, 2011). Twenty (63\%) out of 32 authors providing information literacy definitions in their articles include "evaluate" as an aspect of the definition. However, many do not address each phase of the information literacy process within their reports. 


\section{Information Literacy Training Programs within Nursing}

Several information literacy programs have focused on implementing information literacy skills throughout nursing curricula (Barnard, et al., 2005; Courey, Benson-Soros, Deemer, \& Zeller, 2006; Dorner, Taylor, \& Hudson-Carlton, 2001; Fox, Richter, \& White 1996; Jacobs, Rosenfeld, \& Haber, 2003; Ku, Sheu, \& Kuo, 2007; Staggers, Gassert, \& Curran, 2001; Verhey, 1999; Wallace, Shorten, Crookes, McGurk, \& Brewer, 1999) while one addressed information literacy training in the clinical setting (Rosenfeld, Salazar-Riera, \& Vierira, 2002). According to the literature, there is a direct correlation between education regarding information literacy and self-confidence, which translates to more nurses implementing evidence based practices (Fox et al., 1996; Shorten et al., 2001; Verhey, 1999). Studies show that with increased exposure and knowledge, nursing students' and nurses' perceptions of their information literacy abilities improve (Bickford, et al., 2005; Dorner, Taylor, Hudson-Carlton, 2001; Jacobs, Rosenfeld, \& Haber, 2003; Shorten, Wallace, \& Crookes, 2001; Verhey, 1999). Each identified program was reviewed for personnel involved, level of student targeted, length of program and approach, data collected, focus, and outcomes.

Training programs reviewed were published between the years of 1996 and 2007. Of the nine programs reviewed, seven out of nine (78\%) targeted pre-licensure nursing students and two of the nine $(22 \%)$ focused on programs for graduate nursing students. One program (14\%) included in the review delivered information literacy training to both undergraduate and graduate student nurses.

Similarities were identified among the articles reviewed. Similarities included the use of a librarian and the use of a control group. Eighty-six percent $(86 \%)$ included the consultation of a librarian as an aid in delivering content by way of lecture or discussions with students (Barnard et al., 2005; Dorner et al., 2001; Fox et al., 1996; Jacobs et al., 2003; Verhey, 1999; Wallace et al., 1999;). Five out of seven (71\%) of the articles reviewed revealed that a control group was used when testing the information literacy program (Fox et al., 1996; Jacobs et al., 2003; Ku et al., 2007; Verhey, 1999; Wallace et al., 1999).

Methods of program implementation were mixed among the studies. Length of program delivery varied from three months to education spanning the entire length of the nursing program. Other differences included specific information literacy content being delivered in one course $(\mathrm{Ku}$, Sheu, \& Kuo , 2007) while it was delivered in multiple courses in other programs (Dorner, Taylor, Hudson-Carlton, 2001; Fox, Richter, \& White, 1996) and yet others delivered information literacy content through a series of incrementally complex activities (Barnard, Nash, \& O'Brien, 2005 ;Wallace, Shorten, Crookes, McGurk, \& Brewer 1999).

Most studies reviewed associated positive outcomes with the following: participant confidence levels, increases in the use of online library databases, and faculty reported student improvement in research ability. However, evaluation of programs varied greatly and there was an absence of a standardized evaluation technique for measuring information literacy competencies. Four (50\%) of the programs reviewed used 
subjective approaches for evaluating. These methods include anecdotal reports from faculty on student progress and assessments of student assignments combined with to objective means for evaluating information literacy competencies (Fox et al. 1996; Jacobs et al., 2003; Ku et al., 2007; Wallace et al. 1999). Reports of the three programs suggested that student nurses' perceptions of information seeking skills improved over time. Further Fox et al. (1996) and Jacobs et al. (2003) reported significant increases in students' abilities to use library information resources. Others used quantifiable results of a survey that measured self-perceptions of information literacy skills (Fox et al. 1996; Jacobs et al., 2003; Ku et al., 2007; Wallace et al. 1999). Two (29\%) of the programs reviewed used student assignments, some of which were subjective, to gauge information literacy abilities after students received information literacy content (Dorner et al., 2001; Wallace et al., 1999).

Very few of these programs offered any information about each aspect of the information literacy process and how it was addressed (i.e. assignments pertaining to teaching information appraisal, assignments pertaining to teaching information application). Only two out of nine (22\%) of the programs included offered specific information about the content regarding information evaluation infused into their curricula (Jacobs, Rosenfeld, \& Haber, 2003; Ku, Sheu, and Kuo, 2007). These authors included the teaching strategy or assignment used to address the competency in their articles. The delivery of these two programs delivered with respect to target population (Jacobs, Rosenfeld, \& Habe $\mathrm{r}=$ graduate nursing program; Ku, Sheu, \& Kuo $=\mathrm{RN}$ to BSN program) and length of program (Jacobs, Rosenfeld, \& Haber = throughout entire curriculm; KuSheu, \& Kuo = one semester), however they both included content that addressed information seeking and information evaluation.

Literature reviewed commonly reported the benefits of librarian assistance. Librarian involvement helped to enhance the effectiveness of the program and was considered an integral component to the instruction offered (Barnard, et al., 2005; Dorner, et al., 2001; Fox et al., 1996; Jacobs, et al., 2003; Shorten, et al., 2001; Verhey, 1999). Librarian instruction was a common thread among the information literacy program literature that was reviewed(Barnard, et al., 2005; Dorner, et al., 2001; Fox et al., 1996; Jacobs, et al., 2003; Shorten, et al., 2001; Verhey, 1999). Table 2-1 highlights the results found in this literature review.

\section{Information Appraisal in Nursing}

Information appraisal, a process used by nurses to determine the clinical relevance of information being reviewed, is a step in the information literacy process and is considered to be an important part of EBP (Jutel, 2008; Stevens, 2007). Information appraisal is most commonly associated with appraising research-based information (Parkes, Hyde, Deeks, \& Milne, 2001) The current literature rarely discusses how nurses appraise information in the clinical setting.

Information appraisal engages problem solving techniques by methodically reviewing and evaluating evidence while considering its validity, results, and significance 
Table 2-1. Information Literacy Training Programs in Nursing

\begin{tabular}{|c|c|c|c|c|c|c|}
\hline Author (Year) & $\begin{array}{l}\text { Target } \\
\text { Group }\end{array}$ & $\begin{array}{l}\text { Program } \\
\text { Length }\end{array}$ & Approach & $\begin{array}{l}\text { Type of } \\
\text { Evaluation }\end{array}$ & Instruments & Findings \\
\hline $\begin{array}{l}\text { Fox, Richter, \& } \\
\text { White (1996) }\end{array}$ & $\begin{array}{l}\text { Undergrad- } \\
\text { uate nursing } \\
\text { students }\end{array}$ & $\begin{array}{l}6 \text { hours ( } 4 \text { 1.5- } \\
\text { hour sessions) }\end{array}$ & $\begin{array}{l}\text { Integrated into two } \\
\text { nursing courses. } \\
\text { Librarian } \\
\text { consultation. }\end{array}$ & $\begin{array}{l}\text { Subjective } \\
\text { Objective }\end{array}$ & $\begin{array}{l}\text { Likert scale to } \\
\text { measure } \\
\text { confidence } \\
\text { Campus wide } \\
\text { instrument } \\
\text { administered to } \\
\text { nursing }\end{array}$ & $\begin{array}{l}\text { Confidence levels increased. } \\
\text { Increases in use of computer } \\
\text { databases and application of } \\
\text { search techniques }\end{array}$ \\
\hline Verhey (1999) & $\begin{array}{l}\text { Undergrad- } \\
\text { uate nursing } \\
\text { students }\end{array}$ & $\begin{array}{l}\text { Throughout } \\
\text { nursing } \\
\text { curriculum }\end{array}$ & $\begin{array}{l}\text { Information was } \\
\text { taught by course } \\
\text { faculty and librarian } \\
\text { who is also a nurse. } \\
\text { Pre- and post-testing } \\
\text { was used. }\end{array}$ & Subjective & $\begin{array}{l}\text { 1) Student } \\
\text { question- naire } \\
\text { assess } \\
\text { perceptions of } \\
\text { comfort, use of } \\
\text { resources, and } \\
\text { skill } \\
\text { 2) Faculty } \\
\text { question-naire } \\
\text { assess } \\
\text { perceptions of } \\
\text { students' use of } \\
\text { resources and } \\
\text { skills }\end{array}$ & $\begin{array}{l}\text { Perceptions of improvement } \\
\text { by both students and faculty }\end{array}$ \\
\hline $\begin{array}{l}\text { Wallace, } \\
\text { Shorten, } \\
\text { Crookes, et al. } \\
(1999)\end{array}$ & $\begin{array}{l}\text { Undergradua } \\
\text { te nursing } \\
\text { students }\end{array}$ & $\begin{array}{l}\text { Throughout } \\
\text { one semester }\end{array}$ & $\begin{array}{l}\text { Three incremental } \\
\text { library based } \\
\text { learning activities. } \\
\text { Librarian } \\
\text { consultation. }\end{array}$ & $\begin{array}{l}\text { 1) Subjective } \\
\text { 2) Objective }\end{array}$ & $\begin{array}{l}\text { 1) Direct } \\
\text { observations } \\
\text { 2) Graded } \\
\text { student } \\
\text { assignments }\end{array}$ & $\begin{array}{l}\text { 1) Statistically significant } \\
\text { differences in self-confidence } \\
\text { 2) reported in Shorten, et al. } \\
\text { (2001) }\end{array}$ \\
\hline $\begin{array}{l}\text { Dorner, Taylor, } \\
\text { \& Hudson- } \\
\text { Carlton (2001) }\end{array}$ & $\begin{array}{l}\text { Undergrad- } \\
\text { uate and } \\
\text { graduate } \\
\text { nursing } \\
\text { students }\end{array}$ & 3 semesters & $\begin{array}{l}\text { Integrated in } 3 \\
\text { nursing courses both } \\
\text { undergrad-uate and } \\
\text { graduate level. } \\
\text { Librarian } \\
\text { consultation. }\end{array}$ & Subjective & $\begin{array}{l}\text { Not identified. } \\
\text { Used student } \\
\text { assignments for } \\
\text { assessment }\end{array}$ & $\begin{array}{l}\text { Student feedback positive } \\
\text { with reports of increased } \\
\text { comfort levels }\end{array}$ \\
\hline
\end{tabular}


Table 2-1 (continued)

\begin{tabular}{|c|c|c|c|c|c|c|}
\hline Author (Year) & $\begin{array}{l}\text { Target } \\
\text { Group }\end{array}$ & Program Length & Approach & $\begin{array}{l}\text { Type of } \\
\text { Evaluation }\end{array}$ & Instruments & Findings \\
\hline $\begin{array}{l}\text { Rosenfeld, } \\
\text { Salazar-Riera, \& } \\
\text { Vieira (2002) }\end{array}$ & $\begin{array}{l}\text { ICU Staff } \\
\text { Nurses }\end{array}$ & $\begin{array}{l}1 \text { hour training } \\
\text { session with } \\
\text { follow-up from } \\
\text { Medical } \\
\text { Librarian }\end{array}$ & $\begin{array}{l}\text { Approach: Offered } \\
\text { educational } \\
\text { training sessions }\end{array}$ & Objective & $\begin{array}{l}\text { Pre and post- } \\
\text { test }\end{array}$ & $\begin{array}{l}\text { Majority of staff nurses } \\
\text { remained at no competency } \\
\text { level; others moved to } \\
\text { beginner, intermediate, or } \\
\text { advanced level }\end{array}$ \\
\hline $\begin{array}{l}\text { Jacobs, } \\
\text { Rosenfeld, \& } \\
\text { Haber (2003) }\end{array}$ & $\begin{array}{l}\text { Graduate } \\
\text { nursing } \\
\text { students }\end{array}$ & 1 year & $\begin{array}{l}\text { Integrated into the } \\
\text { curriculum. } \\
\text { Librarian } \\
\text { consultation. }\end{array}$ & Objective & $\begin{array}{l}\text { Surveys to } \\
\text { assess } \\
\text { competency }\end{array}$ & $\begin{array}{l}\text { Improvement in information } \\
\text { literacy skills }\end{array}$ \\
\hline $\begin{array}{l}\text { Barnard, Nash, } \\
\text { \& O'Brien } \\
\text { (2005) }\end{array}$ & $\begin{array}{l}\text { Undergrad- } \\
\text { uate nursing } \\
\text { students and } \\
\text { clinical } \\
\text { nurses }\end{array}$ & $\begin{array}{l}\text { Throughout } \\
\text { nursing } \\
\text { curriculum }\end{array}$ & $\begin{array}{l}\text { Incrementally } \\
\text { complex learning } \\
\text { activities Librarian } \\
\text { consultation. }\end{array}$ & Ongoing & Unknown & Unknown \\
\hline $\begin{array}{l}\text { Courey, } \\
\text { Benson-Soros, } \\
\text { Deemer, et } \\
\text { al.(2006) }\end{array}$ & $\begin{array}{l}\text { Associate } \\
\text { Degree } \\
\text { Nursing } \\
\text { Students }\end{array}$ & 1 semester & $\begin{array}{l}\text { Included specific } \\
\text { assignments } \\
\text { focused on } \\
\text { developing } \\
\text { information } \\
\text { literacy skills }\end{array}$ & Subjective & $\begin{array}{l}\text { Pre and post- } \\
\text { test }\end{array}$ & $\begin{array}{l}\text { Information literacy program } \\
\text { had a positive effect on } \\
\text { nursing students' literacy } \\
\text { skills and a reverse effect on } \\
\text { their attitudes toward the } \\
\text { need for these skills }\end{array}$ \\
\hline $\begin{array}{l}\text { Ku, Sheu, \& Kuo } \\
(2007)\end{array}$ & $\begin{array}{l}\text { Undergrad- } \\
\text { uate (RN- } \\
\text { BSN) } \\
\text { nursing } \\
\text { students }\end{array}$ & 3 months & $\begin{array}{l}\text { Information } \\
\text { Literacy learning } \\
\text { activities were } \\
\text { included in a } \\
\text { Women's Health } \\
\text { course }\end{array}$ & 2) Objective & $\begin{array}{l}\text { 1) Pre and Post } \\
\text { course Likert } \\
\text { scale for self- } \\
\text { evaluation of } \\
\text { information } \\
\text { literacy skills } \\
\text { 2) Information } \\
\text { Literacy Skills } \\
\text { scale }\end{array}$ & $\begin{array}{l}\text { Experimental group was to } \\
\text { have performed significantly } \\
\text { better regarding level of } \\
\text { improvement post-course } \\
\text { intervention }\end{array}$ \\
\hline
\end{tabular}


to the situation. Information appraisal in this study was defined as critically reflecting on and assigning value to acquired information. Reflection on this acquired information provides nurses time to compare and contrast their actions versus what they know which helps inform their decisions. Regarding the information they use, nurses are free to make many choices, which are increasing in number, diversity, and complexity. Research in the area of information literacy and evidence-based practice reveals significant gaps in the abilities of practicing nurses to identify the need for more information, and the ability to access, retrieve, evaluate, and apply evidence (Pravikoff et al., 2005). There are a number of issues that may contribute to this gap including the age of the current nursing workforce, educational experience, and access to information (Hanson et al., 2008).

There is a great need to modify current approaches to education and training pertaining to information appraisal (Cheek, Gillham, \& Ballantyne, 2005). This is in part due to the information explosion and the various forms in which information can occur in the clinical setting. Significant gaps in nurses' abilities to bring forth credible and relevant information into the clinical setting (Hanson, Hoss, \& Wesorick, 2008; Pravikoff, Tanner, \& Pierce, 2005) result in practice often based on tradition, colleagues, or unreliable sources of information. A reason for this void in practice is likely attributed to many complex factors. Nurses are often not taught these skills in nursing school and only a small number of information appraisal programs, all focusing on appraising research-based information have been documented in the literature (Bernardo et al., 2008; Cheek et al., 2005; Ibbotson et al., 1998; Krainovich-Miller, 2009; Land et al., 2002; Miller et al., 2010; Milne et al., 2007).

Developing a range of skills related to information appraisal keeps one poised to provide care based on the most up-to-date evidence. At this time, the most basic research questions should address what information appraisal is and how it is conducted in the clinical setting. Answers to those questions can create solid starting points for further research in the area of information appraisal. This study aims to further expand on what is known about nurses' information appraisal in the clinical setting.

Varying tools have been developed to support information appraisal skills. A study by Katrak et al. (2004) reviewed 121 critical appraisal tools. They found substantial variability among the tools. However, most of these tools have not been validated or widely accepted (Katrak et al., 2004). Only 15 of the tools reviewed addressed psychometric properties. They found that $87 \%$ of tools were specific to a research design, most being designed for experimental studies. Nurses without graduate degrees are often unprepared to use these types of tools for information appraisal (Newhouse et al., 2007).

One important information appraisal skill is being able to recognize relevant and valuable evidence. While it is widely agreed that patient care should be based on evidence, controversy still remains regarding what is considered evidence and how it is used in practice (Banning, 2005; Gerrish et al., 2007; Russell, 2009; Rycroft-Malone et al., 2004). In clinical practice, nurses may seek various forms of evidence such as research, clinical experience, patient experience, patient data, and the experience of colleagues to help them answer questions. This extends Sackett et al.'s (1996) assertion 
that EBP is more than randomized control trials - it includes the knowledge of clinicians and preferences of the patients. Evidence may also be comprised of research findings as well as other sources of credible information such as quality improvement and/or operational data, evaluation data, expert opinion, affirmed clinical experience and patient preferences. These other sources of evidence can be combined with research findings to facilitate decision-making or problem solving (Newhouse, et al., 2007). As these examples show, only a broad definition for evidence can result in the delivery of effective evidence-based care (Rycroft-Malone et al., 2004).

\section{Research-Based Information Appraisal Skills Development}

There are a number of approaches that can be used to help healthcare professionals enhance their critical appraisal skills. Skills associated with information appraisal are often addressed through an academic program, research and evidence-based textbooks, workshops, or through a journal series discussing the specifics of information appraisal. The purpose of this section is to examine studies that have been published that discuss information appraisal training and evaluation.

Twenty information appraisal programs were discovered through this literature review. The programs were published between the years of 1980 and 2009. Of the 20 programs reviewed, only six (30\%) included nursing students and/or professional nurses (Bernardo et al., 2008; Cheek, Gillham, \& Ballantyne, 2005; Ibotson, Grimshaw, \& Grant, 1998; Krainovich-Miller, Haber, \& Jacobs, 2009; Land, Ward, \& Taylor, 2002; Milne, Krishnasamy, Johnston, \& Aranda, 2007). Programs designed for graduate students were often delivered during the students' graduate curriculum, while the programs designed for healthcare professionals were delivered in the form of workshops.

The programs were highly heterogeneous. Variation existed in regard to the content, training techniques, delivery logistics, context, population, and outcome measures. In addition, there were inconsistencies in how these programs were reported in the literature. For example, some authors provided very detailed information about study design, the number of times a program was offered, length of each program session, the program context, and the number and type of participants in each session. Meanwhile, other authors provided very general information about their program schedule, participants, and the results. Further, there were often disparities in how program outcomes were discussed. Some programs offered very detailed information on pre- and post-test data and others offered only general information about success or anecdotal comments from participants. These variations in reporting styles among authors made comparisons across studies problematic.

A variety of study design types were reported by the authors. Most programs reported an improvement related to some aspect of the content that was offered to participants. Twelve $(60 \%)$ of the programs included in this review used a pre- and posttest design to measure outcomes. Two authors did not report outcome measures but dedicated their publication to the description of the program. The specific details about 
Table 2-2. Research-based Information Appraisal Programs in Nursing

\begin{tabular}{|c|c|c|c|c|c|c|}
\hline $\begin{array}{l}\text { Author } \\
\text { (Year) }\end{array}$ & $\begin{array}{l}\text { Number of } \\
\text { Participants }\end{array}$ & Population & Design & Content Delivery & Findings & Discipline \\
\hline $\begin{array}{l}\text { Ibbotson, } \\
\text { Grimshaw, } \\
\text { \& Grant } \\
\text { (1998) }\end{array}$ & 86 & $\begin{array}{l}\text { Medical, } \\
\text { Managerial, } \\
\text { Nursing, and Other }\end{array}$ & Pre/Post Test & $\begin{array}{l}\text { Maximum attendance } \\
\text { allowed - } 2 \text { workshops }\end{array}$ & $\begin{array}{l}\text { Increased scores on understand-ding } \\
\text { of clinical effectiveness }\end{array}$ & $\begin{array}{l}\text { Medicine } \\
\text { Nursing }\end{array}$ \\
\hline $\begin{array}{l}\text { Land, Ward, } \\
\text { \& Taylor } \\
(2002)\end{array}$ & 45 & $\begin{array}{l}\text { Nursing and Allied } \\
\text { Health } \\
\text { Professionals }\end{array}$ & $\begin{array}{l}\text { Post-program } \\
\text { evaluation }\end{array}$ & Not specified & Positive post workshop evaluations & $\begin{array}{l}\text { Nursing } \\
\text { Medicine } \\
\text { Allied Health }\end{array}$ \\
\hline $\begin{array}{l}\text { Cheek, } \\
\text { Gillham, \& } \\
\text { Ballantyne } \\
(2005)\end{array}$ & $\begin{array}{l}\text { Not } \\
\text { identified }\end{array}$ & $\begin{array}{l}\text { Graduate nursing } \\
\text { students }\end{array}$ & N/A & Not specified & $\begin{array}{l}\text { Training program provides an } \\
\text { efficient and practical approach to } \\
\text { integration or nursing research, } \\
\text { education, practice designed }\end{array}$ & Nursing \\
\hline $\begin{array}{l}\text { Milne, } \\
\text { Krishnasam, } \\
\text { Johnston, et } \\
\text { al. (2007) }\end{array}$ & $7 \& 8$ & $\begin{array}{l}\text { Nurses and Allied } \\
\text { Health } \\
\text { Professionals }\end{array}$ & $\begin{array}{l}\text { Cross-sectional } \\
\text { qualitative } \\
\text { evaluation } \\
\text { survey }\end{array}$ & Over 12 weeks & $\begin{array}{l}\text { Program was a benefit to } \\
\text { participants by increasing } \\
\text { confidence, knowledge, and skill. }\end{array}$ & $\begin{array}{l}\text { Nursing } \\
\text { Allied Health }\end{array}$ \\
\hline $\begin{array}{l}\text { Bernardo, } \\
\text { Matthews, } \\
\text { Kaufmann, } \\
\text { et al. } \\
(2008)\end{array}$ & 46 & $\begin{array}{l}\text { School nurses and } \\
\text { nursing students }\end{array}$ & $\begin{array}{l}\text { Post-program } \\
\text { evaluation } \\
\text { survey }\end{array}$ & 1-day workshop & $\begin{array}{l}\text { Participants rated faculty in } \\
\text { workshop highly, however, intent to } \\
\text { apply new skills was "moderate at } \\
\text { best" }\end{array}$ & Nursing \\
\hline $\begin{array}{l}\text { Krainovich- } \\
\text { Miller, } \\
\text { Haber, Yost, } \\
\text { et al. } \\
(2009)\end{array}$ & $\begin{array}{l}\text { Not } \\
\text { identified }\end{array}$ & $\begin{array}{l}\text { Graduate Student } \\
\text { Nurses }\end{array}$ & N/A & $\begin{array}{l}\text { Through research } \\
\text { course }\end{array}$ & $\begin{array}{l}\text { Faculty who use training model } \\
\text { will help grad student address the } \\
\text { claim that they lack time to conduct } \\
\text { search and critically appraise } \\
\text { evidence }\end{array}$ & Nursing \\
\hline
\end{tabular}


training programs for nurses included in this review are found in the Research-based Information Appraisal Programs in Nursing Table 2-2.

Overall, the positive results reported by authors of these studies included in this review offers encouragement for the body of knowledge surrounding information appraisal and evidence-based practice. Information appraisal skills are valued by healthcare professionals and results indicate that training can be helpful and effective. There is a lack of consensus on how information appraisal skills should be taught and addressed. Information appraisal skills can help address the challenges of keeping up with research literature and thus improving the incorporation of research findings into practice.

\section{Web-Based Information Appraisal Skills Development}

The information explosion presents challenges to the incorporation of evidence into practice (Gosling, Westbrook, \& Spencer, 2004). The Internet is used by physicians and nurses to find additional information in the clinical setting. However, Cullen (2002) reported that practitioners need more training in searching and evaluating Internet based information.

Several organizations have developed criteria to assist in evaluating information found online health-related information including HON Code, American Medical Association, Internet Health Care Coalition, Hi-Ethics, and MedCertain (Berland et al., 2001). These criteria vary in scope and are not generated or shared in a systematic way. Furthermore, many were designed to evaluate health and medical information but no specific criteria that relate to nursing (Cader, 2003).

Nurses must be aware of the variation and characteristics of online information (Gilmour, Scott, \& Huntington, 2007). Usher (2009) reported that general practitioners possess "limited knowledge" of what comprises a reliable website (p. 43). They add that healthcare practitioners must improve their own skills to help direct patients to reliable web-based health information. Verhoeven et al. (2009) found that not only were nurses were weak in information seeking skills as evidenced by limited number of search terms and limited number of websites consulted. Criteria such as disclosures and accuracy, which are emphasized in the e-health literature, were not considered important. Studies regarding online information appraisal varied in regard to the study aim and study population. The designs used were either quantitative using a questionnaire or qualitative design. The majority (57\%) of studies based findings on questionnaire data. Table 2-3 highlights the variations in programs.

\section{Conclusion}

Nurses need the ability to evaluate information as they influence decisions made about patient care. Therefore, information appraisal skills are necessary for nurses to apply best practices in modern heath care settings that are more information rich than 
Table 2-3. Web-Based Information Appraisal Skills Programs

\begin{tabular}{|c|c|c|c|c|}
\hline $\begin{array}{l}\text { Author } \\
\text { (Year) }\end{array}$ & $\begin{array}{l}\text { \# of } \\
\text { Partici- } \\
\text { pants }\end{array}$ & Sample & Results & Discipline \\
\hline $\begin{array}{l}\text { Cullen } \\
(2002)\end{array}$ & 363 & General practitioners & $\begin{array}{l}48.6 \% \text { reported they used the Internet for clinical information. Practitioners need } \\
\text { more training in searching and evaluating Internet information }\end{array}$ & $\begin{array}{l}\text { Health Science } \\
\text { Librarian }\end{array}$ \\
\hline $\begin{array}{l}\text { Cader, } \\
\text { Campbell, \& } \\
\text { Watson } \\
(2003)\end{array}$ & 7 & $\begin{array}{l}\text { Post-registration } \\
\text { student nurses }\end{array}$ & $\begin{array}{l}\text { Categories for evaluating web-based information emerged. Categories included } \\
\text { publication source, author's background, evidence-based, practice-related } \\
\text { information, intuition, Internet usage, medium differences, information quality, } \\
\text { user-friendliness, and the nature of information. }\end{array}$ & Nursing \\
\hline $\begin{array}{l}\text { Gosling, } \\
\text { Westbrook, \& } \\
\text { Spencer } \\
(2004)\end{array}$ & 3128 & Nursing staff & $\begin{array}{l}\text { Senior nurses had the greatest awareness of a website offering online access to } \\
\text { evidence. }\end{array}$ & Nursing \\
\hline $\begin{array}{l}\text { Gilmour, } \\
\text { Scott, \& } \\
\text { Huntington } \\
(2007)\end{array}$ & 123 & $\begin{array}{l}\text { Postgraduate nursing } \\
\text { students }\end{array}$ & $\begin{array}{l}\text { Concern was expressed about the quality of online information. Some participants } \\
\text { assessed their patients' use of online information }\end{array}$ & Nursing \\
\hline $\begin{array}{l}\text { Cader, } \\
\text { Campbell, \& } \\
\text { Watson } \\
(2009)\end{array}$ & 33 & $\begin{array}{l}\text { Graduate nursing } \\
\text { students and nurses }\end{array}$ & $\begin{array}{l}\text { Data collected suggests that during evaluation nurses use three different modes of } \\
\text { cognition (intuitive, quasi-rationale, and analytical. Nurses use these modes based } \\
\text { on their critical skill level, cues presented in the online resource, and time } \\
\text { available. }\end{array}$ & Nursing \\
\hline Usher, 2009 & 90 & General practitioners & $\begin{array}{l}\text { Participants demonstrated a range of understanding and critical appraisal skills } \\
\text { used to determine the reliability, interactivity, and usability of a health website }\end{array}$ & $\begin{array}{l}\text { Education and } \\
\text { Professional } \\
\text { Studies }\end{array}$ \\
\hline $\begin{array}{l}\text { Verhoeven, } \\
\text { Steehouder, } \\
\text { Hendrix, et al. } \\
(2009)\end{array}$ & 20 & Nurses & $\begin{array}{l}\text { Accuracy and disclosures which are emphasized in the e-health literature were } \\
\text { considered less important than other criteria. Nurses were satisfied if information } \\
\text { matched nurses' practical and experiential wisdom. }\end{array}$ & Psychology \\
\hline $\begin{array}{l}\text { Miller et al. } \\
(2010)\end{array}$ & $\begin{array}{c}204 \& \\
407\end{array}$ & $\begin{array}{l}\text { Public health nurses } \\
\text { and school nurses }\end{array}$ & $\begin{array}{l}\text { Nurses most valued knowing about the array of reliable credible web based health } \\
\text { information resources, learning how to evaluate website credibility, learning how } \\
\text { to locate and apply professional literature in practice }\end{array}$ & Nursing \\
\hline
\end{tabular}


ever before. The topic of information appraisal within the clinical setting is largely absent from the nursing literature. While many authors use various terms to describe the information appraisal process, no common definition seems to exist (Parkes, Hyde, Deeks, \& Milne, 2007). Findings from this review, while limited, have implications for nursing practice in the areas of academic and clinical education and evidence-based practice. Nurses have an obligation to provide the highest quality care based on evidence and therefore should be mindful of the importance of developing their information appraisal skills when opportunities in practice arise.

Information appraisal, a key to EBP (Stevens, 2007), is a process that is used to determine the clinical relevance and credibility of information being reviewed. The current body of literature pertaining to information appraisal in nursing rarely discusses how nurses appraise information in the clinical setting. Much of what is offered consists of checklists or criteria that may be used to evaluate information.

The type of research-based (qualitative, quantitative, or mixed methods, research or non-research-based) information accessed by practicing nurses varies widely. The range of quality also varies, ranging from systematic reviews of nursing research to information located on the Internet that may have low integrity (Cheek, Gillham, \& Ballantyne, 2005). Just as there are different types of information, there are different approaches to appraising information. The appraisal technique should correlate with the type of information being evaluated (Ryan, Coughlan, \& Cronin, 2007). Checklists and criteria to evaluate research-based information exist. Without specific training in the area of research-based information appraisal, it is often difficult to know how to apply checklists and criteria used to evaluate information. Because many nurses have not been taught information appraisal skills, a gap exists with implementing nursing practice based on evidence (Newhouse et al., 2007).

Given the state of the literature and the results of the literature synthesis, it would be premature to provide specific conclusions on best practices of information appraisal programs and suggestions for criteria to use when evaluating information. With the current state of the literature, it is very difficult to compare information appraisal and information appraisal training programs and between, discipline, clinical or community settings and information appraisal criteria. Though some articles have reported data and specific results in quantifiable terms, others offer only anecdotal reports of user experience or participant evaluation feedback. Reporting program design, details, approach, and results vary among the few articles that exist adding to the complexity of the analyses.

Answers to the questions "How is information appraisal best taught?," "How can we facilitate information appraisal in nursing work environments?" and "What criteria should be used to evaluate the different types of evidence?" would be helpful. However, the most basic research should address what information appraisal is and how it is conducted in the clinical setting. Answers to those questions can create solid starting points for further research in the area of information appraisal. This study aims to further expand on what is known about nurses' information appraisal in the clinical setting. 
Challenges were identified in reviewing the highly heterogeneous literature surrounding information literacy training programs in nursing and information appraisal skills training. The current study sought to describe information appraisal and how nurses performed it in the clinical setting. 


\section{CHAPTER 3. METHODS}

\section{Introduction}

Because little is known about the information appraisal of nurses, a qualitative, interpretive description design (Thorne, 2008) was used to explore the process within the clinical setting. The methods, population, sampling and recruitment techniques, sample, instruments, and the data collection procedures are described in this chapter.

\section{Research Design: Interpretive Description}

Interpretive description facilitates the explanation of patterns and themes that materialize with respect to clinical phenomena. This method offers an opportunity to answer research questions and subsequently describe the process of information appraisal by nurses in the clinical setting. A descriptive exploratory method such as interpretive description was fitting for this research topic, about which little is known (Thorne, 2008).

The method of interpretive description was developed as a response to a widely recognized need within qualitative research. While traditional qualitative research methods (such as grounded theory, ethnography, and phenomenology) lend themselves to the study of various topics, many of such studies have not followed the rules set forth for those methods. Thus, interpretive description was developed as a result of problems associated with understanding qualitative methods and their usefulness (Thorne, 2008). Interpretive description is a purposeful and sound method that can be used by novice qualitative scientists. It is a qualitative methodological option that allows the researcher to use specific qualitative research techniques in practical situations, such as the clinical setting (Thorne, 2008).

In the current study, the interpretive description method fit the research situation, including questions, purposeful sampling, focus group data collection strategies, comparisons of similarities and differences and proved useful in creating nursing practice knowledge. Interpretive description guided the exploration of relationships between concepts articulated by focus group participants responding to questions asked in interviews.

\section{Data Collection Strategy: Focus Groups}

Focus groups can be useful at any stage in research but are very helpful when little is known about the concept of interest: "when little is known about a particular subject or certain phenomenon, there are few alternatives" (Stewart \& Shamdasani, 1990, p. 18). For the purposes of this study, focus groups were used to obtain general information about the information appraisal process among nurses. The focus groups allowed for further examination of nurses' descriptions and discussions related to information appraisal and their perceptions about how they appraise information. Focus 
groups promoted further explanation by participants that may not have been gained through individual interviews (Krueger \& Casey, 2000).

Best practices of focus group methods guided this study. The best practices in this study included 1) the number of groups, 2) group size, and 3) purposeful sampling. The number of groups needed to reach saturation (the point at which no new insights are gained) varies, but it is standard to plan for three to five focus groups (Morgan, 1998). A group size of seven to ten participants is preferred because too few participants can cause challenges in stimulating discussion (Stewart \& Shamdasani, 1990), while too many participants can limit discussion opportunities for individual participants (Krueger \& Casey, 2000). Further, focus group research necessitates purposeful sampling. In order to create an environment for productive group discussion, each focus group should be composed of homogeneous strangers (Stewart \& Shamdasani, 1990). Homogeneity of the group encourages participant comfort in sharing within the group.

\section{Setting}

To capture the contextual and unique nature of nurses' experiences with information appraisal, the decision was made to conduct this study in a clinical setting at a facility offering a number of information resources for practicing nurses. The setting for this study was the Druid City Hospital (DCH) Regional Medical Center in Tuscaloosa, Alabama. DCH is a 583-bed regional medical center in west Alabama offering a variety of specialty care units and services. The facility was equipped with an information system used for patient care. The facility offers numerous current Intranet information resources for nurse to use at the point-of-care including Micromedex, Ovid, and Up-To-Date. The work flows and documentation requirements at the facility require nurses to access computers and information frequently in patient care situations.

\section{Purposeful Sampling}

A stratified purposeful sampling technique was used to ensure that particular subgroups of interest were uniformly represented in the sample distribution (Patton, 2002). The stratifications that result can facilitate comparisons between groups that represent important aspects or divisions of the concept of interest. Because of their unique knowledge and position within the organization, the Nurse Educators at DCH were poised to inform the principal investigator. The nurse educators at DCH are assigned specific units and have working knowledge of the day-to-day activities of each unit. The educators worked closely with the nursing units at DCH to offer workshops specific to new clinical information and to offer opportunities for continuing education. In addition, the nurse educators have knowledge of scheduling patterns, each unit's overall educational offering participation, level of nursing expertise, licensure status of nurses, and culture among their assigned units. It was assumed that the nurse educators as a group would possess more in-depth knowledge about the nursing units and therefore, be able to inform the PI in an effort to purposefully sample the population. 
Each nurse educator was asked to participate in the study sampling process. Seven nurse educators agreed to participate in a 1.5 hour meeting with the researcher. The educators were asked to establish criteria for evaluating their perception of educational participation associated with each DCH nursing unit. Criteria established by the nurse educators included the overall unit participation in educational opportunities, nurse manager inquiries, nursing staff inquiries, and pilot unit status. Next, the nurse educators rated each criteria numerically on a three-point scale (3-High, 2-Mid, 1-Low). It was thought that there may be differences between the three categories (or stratifications) with respect to the nurses' knowledge about information appraisal. Based on the quantitative results of this evaluation, the nurse educators arrived at a ranked list of units. Twenty inpatient units employing 796 registered nurses were selected for purposeful sampling. Focus group recruitment resulted in the participation of 20 units employing 796 nurses were selected for purposeful sampling. Eight units were rated as High, five were rated as Middle, and seven were rated as Low by the nurse educators.

\section{Recruitment}

Nurses regularly scheduled to work on units ranked in the High category were recruited first for two reasons. First, it was believed those nurses would be more likely to

participate in a research study. Second, it was believed that nurses in High category units would have the most to say on the topic. This strategy was believed to generate the most feedback early in the recruitment approach to allow for any needed modifications. The recruitment process involved placing a flyer (Appendix A) into individual nurses' mailboxes located on the nursing units. The recruitment flyer had information about the focus group topic, amount of time required for participation, contact information for the principal investigator, and information about incentives (\$25 gift card and light refreshments). The type and value of the incentive was consistent with asking each person to participate in a 90-minute group discussion (Krueger \& Casey, 2000).

It was discovered during the initial delivery of fliers that not all nurses used their mailboxes for receiving information. In addition, it was discovered that some units were not equipped with mailboxes for their nurses. The principal investigator consulted with administrators and nurses managers at DCH to develop an alternative plan for delivering the fliers to nurses. It was decided that the principal investigator could place fliers in all unit break rooms and an additional poster flier was created to post on break room bulletin boards with permission of nursing unit managers. The principal investigator also received permission to attend unit meetings and deliver a brief (less than 5 minute) informative presentation about the study in an effort to make contact with interested individuals. IRB approval was sought and obtained for the aforementioned addendums to the recruitment strategy.

Interested nurses were instructed to contact the principal investigator via email or phone to indicate their interest in participating in a focus group. Once they contacted the principal investigator, individuals were considered potential participants and their contact information was recorded. Potential participants were scheduled for a focus group based on their unit affiliation and a convenient time off-shift. Once the individual agreed to 
participate in a specific focus group an email was sent that included information on focus group time, location, incentive, and contact information for the principal investigator. The email also explained that the interview would be audio recorded and identifiers would not be collected. A reminder phone call and email were sent one day prior to the potential participant's scheduled focus group (Krueger \& Casey, 2000). All contact information was stored in a password protected file only accessible by the principal investigator.

Although recommendations for the number of participants in a focus group vary, the minimum number of participants suggested by focus group experts is four (Krueger \& Casey, 2000). A minimum of ten participants were invited to each focus group. This oversampling reduced the risk of the cancellation of any focus group, which would have necessitated the re-recruitment of some participants, decreased possible retention in the study, and diminished the reputation of the project within any affected participants.

\section{Sample}

Stratified purposeful sampling gave credibility because very little understanding existed regarding key concepts and relationships associated with information appraisal. The ranked list determined by the nurse educators was used to place each nursing unit in one of the three strata (High, Mid, or Low), each having two focus groups. This process allowed the principal investigator to maintain control of both subject selection and group composition (Krueger \& Casey, 2000). It also ensured that each focus group was homogeneous based on the degree of interaction or connectivity with the nurse educators. As a result, participants were representative of the groups (High, Mid, and Low) intended to study.

All three strata were represented in a seventh focus group, which was used for validation purposes. The seventh focus group was used to lend credibility to the study and to establish meaningfulness of the findings (Lincoln \& Guba, 1985). Data synthesized by the researcher was presented to the participant in the form of three different scenarios. Participants were asked about the types of resources they would use in each scenario and the reasons they would trust the resource. Participants validated the scenarios and the data synthesized at that point in the study.

Participants represented a purposeful sample of 44 registered nurses providing direct patient care in the inpatient setting at DCH. A detailed description of the sample is located in Table 3-1. Of the 44 participants, three (7\%) were male and 41 (93\%) were female. Participants were between the ages of 21 and $60($ mean $=42.84 ; S D=10.8)$. Participants had been licensed as a registered nurse anywhere from one year to 38 years $($ mean $=16.05 ; S D=10.2)$. Nineteen $(43 \%)$ of participants were prepared as a nurse by way of an Associate's Degree and $6(14 \%)$ held graduate degrees (i.e., at least a MSN or doctorate) in nursing. At the time of the study five (12\%) participants reported to be pursuing additional formal nursing education. Most participants reported spending the greater part of their work week in a general/specialty inpatient unit. 
Table 3-1. Demographic Characteristics of Participants $(\mathrm{N}=44)$

\begin{tabular}{|c|c|c|}
\hline Characteristics & $\mathrm{n}$ & $\%$ \\
\hline \multicolumn{3}{|l|}{ Gender } \\
\hline Male & 3 & 7 \\
\hline Female & 41 & 93 \\
\hline \multicolumn{3}{|l|}{ Age at time of survey (years) } \\
\hline $20-29$ & 6 & 13 \\
\hline 30-39 & 13 & 30 \\
\hline $40-49$ & 11 & 25 \\
\hline $50-59$ & 13 & 30 \\
\hline $60-69$ & 1 & 2 \\
\hline \multicolumn{3}{|l|}{ Years licensed as a registered nurse (years) } \\
\hline $0-5$ & 9 & 21 \\
\hline $6-10$ & 5 & 11 \\
\hline $11-15$ & 7 & 16 \\
\hline $16-20$ & 8 & 18 \\
\hline $21-25$ & 7 & 16 \\
\hline $26-30$ & 4 & 9 \\
\hline $31-35$ & 3 & 7 \\
\hline $36-40$ & 1 & 2 \\
\hline \multicolumn{3}{|l|}{ Initial Education Program Qualifying Participant for RN } \\
\hline \multicolumn{3}{|l|}{ Licensure } \\
\hline Diploma Program & 1 & 2 \\
\hline Associate Degree & 26 & 59 \\
\hline Bachelor's Degree & 17 & 39 \\
\hline \multicolumn{3}{|l|}{ Currently enrolled in education program*(missing data) } \\
\hline Yes & 5 & 12 \\
\hline No & 38 & 88 \\
\hline \multicolumn{3}{|l|}{ Academic Degrees Earned } \\
\hline Associate Degree in Nursing & 23 & 52 \\
\hline Associate Degree in Another Field & 6 & 14 \\
\hline Bachelor's Degree in Nursing & 20 & 45 \\
\hline Bachelor's Degree in Another Field & 4 & 9 \\
\hline Master's Degree in Nursing & 5 & 11 \\
\hline Doctorate in Nursing & 2 & 5 \\
\hline Not Applicable & 2 & 5 \\
\hline \multicolumn{3}{|l|}{ Area of Majority of Time Spent in Typical Work Week } \\
\hline $\mathrm{CCU} / \mathrm{ICU}$ & 9 & 20 \\
\hline Education & 1 & 2 \\
\hline Emergency Department & 2 & 5 \\
\hline $\begin{array}{l}\text { General/Specialty Inpatient Unit (other than critical } \\
\text { care or stepdown) }\end{array}$ & 11 & 25 \\
\hline Labor/Delivery Room & 3 & 7 \\
\hline Operating Room & 3 & 7 \\
\hline Stepdown, Transitional, Progressive, Telemetry & 1 & 2 \\
\hline
\end{tabular}


Table 3-1 (continued)

\begin{tabular}{ccc}
\hline Characteristics & $\mathrm{n}$ & $\%$ \\
\hline Multiple Units, none over 50\% & 3 & 7 \\
Other & 11 & 25 \\
\hline
\end{tabular}


There were an average of six participants in each focus group (range $=4-9$; $S D=1.75$ ) and each focus group lasted an average of 56 minutes (range $=43-68$; $S D=9.33$ ). Sixteen out of 20 eligible nursing inpatient units within the facility were represented. Participants working days, evening, nights, per diem, and weekends were represented in the sample. A detailed description of the focus group characteristics can be found in Table 3-2.

The principal investigator collected information about unit and primary shift during enrollment to control for group composition. Participants were homogeneous in that they worked in the same facility, had access to similar resources in the clinical units, and worked with similar patient populations. Participants were invited to focus groups with other nurses (i.e. "strangers") who did not work on the same schedule and/or unit. This allowed for participant variation within focus groups and for the researcher to avoid situations that may have inhibited the disclosure of information on certain topics because of work relationships.

All participants in each group were believed to be strangers and great effort was made by the principal investigator to assure that all participants were not close coworkers and did not work the same shift. By controlling for this group composition it was thought to facilitate greater discussion by providing a more anonymous environment within which to disclose any necessary details about work-related experiences. However, coming from the same organization, it is possible that some participants within any group may have known each other.

\section{Instruments}

Two data collection instruments were used. First, a demographic questionnaire was completed by each focus group participant (Appendix B). The demographic questionnaire was developed over multiple studies with the first version used in the Health Resources and Services Administration (HRSA) 2004 National Sample Survey of Registered Nurses. That version was adapted and used in the Learning Information Seeking and Technology for Evidence-based Nursing (LISTEN) project, which was a three-year (2008-2010) project funded by HRSA to enhance nurses' information literacy. The demographic questionnaire collected data on age, gender, years licensed as a registered nurse, educational history, primary nursing unit, and whether or not the participant was a nurse manager.

An investigator-developed semi-structured focus group interview guide (Appendix C) was used by the focus group moderator during each focus group session. The semi-structured interview guide ensured standardization of questioning and assisted the principal investigator in collecting common information from each group (Morgan, 1998). The following categories of questions were used: (1) opening questions, (2) introductory questions, (3) transition questions, (4) key questions and (5) ending questions (Morgan, 1998). Consistent with qualitative research 
Table 3-2. Focus Group Characteristics

\begin{tabular}{|c|c|c|c|c|c|c|c|c|}
\hline $\begin{array}{l}\mathrm{FG} \\
\# \\
\end{array}$ & $\begin{array}{l}\text { Stratifica- } \\
\text { tion } \\
\text { Category } \\
\end{array}$ & $\begin{array}{c}\text { \# of } \\
\text { Parti- } \\
\text { cipants }\end{array}$ & $\begin{array}{l}\text { Durati } \\
\text { on } \\
\text { (min.) }\end{array}$ & Gender & $\begin{array}{c}\text { Age } \\
\text { Average (Range) } \\
\text { SD } \\
\end{array}$ & $\begin{array}{c}\text { Years Licensed } \\
\text { Average (Range) } \\
\text { SD }\end{array}$ & $\begin{array}{c}\# \\
\text { (Units } \\
\text { Represented) } \\
\end{array}$ & $\begin{array}{c}\text { Shifts } \\
\text { Represented } \\
\end{array}$ \\
\hline 1 & High & 6 & 36 & $\begin{array}{c}M=0 \\
F=6\end{array}$ & $\begin{array}{c}41(27-55) \\
S D: 10.5\end{array}$ & $\begin{array}{c}17(5-32) \\
S D: 11.02\end{array}$ & $\begin{array}{c}3 \\
\text { (Periop, ED, } \\
\text { Peds) }\end{array}$ & $\mathrm{D} / \mathrm{E}$ \\
\hline 2 & Mid & 9 & 55 & $\begin{array}{l}M=2 \\
F=7\end{array}$ & $\begin{array}{l}44(28-60) \\
S D: 11.17\end{array}$ & $\begin{array}{l}14(2-26) \\
S D: 9.99\end{array}$ & $\begin{array}{c}4 \\
\text { (CRT, MICU, } \\
\text { WBN/NICU, } \\
\text { ACCU) }\end{array}$ & $\mathrm{E} / \mathrm{N} / \mathrm{D}$ \\
\hline 3 & Mid & 7 & 43 & $\begin{array}{l}M=0 \\
F=7\end{array}$ & $\begin{array}{l}37(22-55) \\
S D: 13.00\end{array}$ & $\begin{array}{l}12(<1-25) \\
S D: 10.23\end{array}$ & $\begin{array}{c}3 \\
(5 \mathrm{C} / \mathrm{N}, \mathrm{MICU}, \\
\mathrm{ACCU})\end{array}$ & $\mathrm{N} / \mathrm{D}$ \\
\hline 4 & High & 7 & 64 & $\begin{array}{l}M=0 \\
F=7\end{array}$ & $\begin{array}{l}51(40-59) \\
S D: 7.78\end{array}$ & $\begin{array}{l}22(15-27) \\
S D: 7.85\end{array}$ & $\begin{array}{c}5 \\
(7 \mathrm{C} / \mathrm{N}, 6 \mathrm{~S}, \\
\text { ER, Peds, 4S) }\end{array}$ & $\mathrm{D} / \mathrm{E} / \mathrm{N}$ \\
\hline 5 & Low & 5 & 65 & $\begin{array}{l}M=0 \\
F=5\end{array}$ & $\begin{array}{c}38(30-45) \\
S D: 6.08\end{array}$ & $\begin{array}{l}13(3-22) \\
S D: 8.35\end{array}$ & $\begin{array}{c}4 \\
(\mathrm{OB}, \mathrm{L} / \mathrm{D}, \\
7 \mathrm{~S}, \mathrm{TSU})\end{array}$ & $\mathrm{N} / \mathrm{D} / \mathrm{WN}$ \\
\hline 6 & Low & 4 & 64 & $\begin{array}{l}M=0 \\
F=4\end{array}$ & $\begin{array}{l}36(21-50) \\
S D: 11.85\end{array}$ & $\begin{array}{l}13(1-28) \\
S D: 11.38\end{array}$ & $\begin{array}{c}3 \\
(\mathrm{O} / \mathrm{B}, \mathrm{L} / \mathrm{D} \\
\mathrm{TSU})\end{array}$ & $\mathrm{D} / \mathrm{WN} / \mathrm{PRN}$ \\
\hline 7 & Combined & 6 & 68 & $\begin{array}{l}M=0 \\
F=6\end{array}$ & $\begin{array}{c}48(37-56) \\
S D: 8.38\end{array}$ & $\begin{array}{l}20(1-32) \\
S D: 12.88\end{array}$ & $\begin{array}{c}4 \\
\text { (CRT, 7C/N, } \\
\text { 2SE, Peds) }\end{array}$ & $\mathrm{D} / \mathrm{N} / \mathrm{PRN}$ \\
\hline
\end{tabular}

Notes: FG, focus group; SD, standard deviation; Min = Minutes; D = Days; E = Evening; $\mathrm{N}=$ Nights; WN = Weekend Nights; $\mathrm{PRN}=$ Per Diem 
practices, whereby initially developed investigator questions typically undergo minor modifications upon initial use in the field with participants (Krueger, 1998), the semistructured focus group interview guide underwent minor modifications in question style and sequencing.

Several minor modifications to the sequencing and wording of questions were necessary as data collection progressed. First, the sequence of questions on note cards used by the participants was modified. The purpose of the note cards was to prompt participants to describe a situation in which they needed more information. Therefore, the logic flow of their responses was influenced by the order of the questions on the note card. Second, the initial question asking participants to define information appraisal was moved to the end of the interview guide. Early in data collection, having this question first produced some responses indicating confusion on the part of the participants. This change allowed participants to become more familiar with the topic before answering this question. Third, redundancy was noted in responses to the question that asked about the format in which information was found. Prompts associated with this question were resequenced in order to reduce redundancy. Additionally, the moderator offered an example of appraising information by describing a personal scenario not related to the clinical setting. This helped participants to visualize and articulate legitimate situations more clearly. Throughout data collection, the effects of these changes were observed in subsequent focus groups. After each subsequent focus group, a debriefing of the moderator, assistant, and methods expert focused on the changes. The responses consistently were more focused on the intended area and became more complete. In all cases, modifications were considered beneficial and effective according to the principal investigator and the methods expert associated with the study.

\section{Data Collection Procedures}

Seven focus groups were conducted between March 2011 and June 2011. Two focus groups represented each of the three stratification categories (High, Mid, Low) and a final follow-up focus group was comprised of participants representing all three stratifications.

A skilled moderator and an assistant conducted all of the focus groups. The use of a skilled moderator is key to having trustworthy focus group results. Moderators must know when it is appropriate to use probing questions and maintain balance of feedback from participants in the group by encouraging those that are not responding as often and controlling those that are talking too much. In addition to using a skilled moderator, an assistant participated during each focus group. The use of an assistant enhanced quality control and improved subsequent analysis. The assistant focused primarily on taking notes on important aspects and primary ideas of the discussion. This allowed the moderator to stay focused on moderating the group discussion without diversion. These notes were later helpful as a reference in the analysis (Krueger, 1993). The seating diagram was useful in recalling the identifications of participants during the transcription stage. 
The first two focus groups were led by a moderator supported by the principal investigator in the role of assistant. The remainder of the groups were led by the principal investigator in the role of the moderator, who was supported by an experienced focus group researcher acting as assistant. In each case, the moderator role involved facilitating the group interview allowing thoughts to materialize from the group and keeping participants engaged and focused on the questions being asked. The assistant took notes, attended to the audio recordings, and addressed any additional special needs that occurred such as answering individual questions about the demographic form or assisting with refreshments (Patton, 2002). Consistent with best practices (Krueger \& Casey, 2000), each focus group was scheduled for 1 to 1.5 hours in order to allow for a thorough discussion of the topic and increase participation.

At the start of the focus group, participants were given a consent form (Appendix E). Once all consent forms were collected, participants completed the demographic questionnaire. Once all demographic questionnaires were completed and collected by the moderator or assistant, audio recording of the focus group interview began. The moderator began asking specific questions of the participants and facilitated the discussion. Focus group interviews were recorded using a digital audio recorder and two back-up audio recorders. Focus group recordings were transcribed within 14 days of the interview. Individual focus groups were assigned a sequential number, for purposes of analysis. Data were transcribed into an electronic document labeled for each focus group.

The semi-structured focus group interview guide was used by the moderator to organize the questioning. Using the guide, the moderator asked questions in a particular sequence, used prompts to ask participants to provide more information or clarification, sought confirmation of key points of the session by summarizing in one to two minutes at the end of each focus group session, and sought final statements from focus group participants. After each focus group an audio-recorded debriefing meeting between the moderator and the assistant occurred. . This meeting was audio recorded as they reviewed the Debriefing Checklist (Appendix D). The moderator and the assistant met immediately after each focus group. This debriefing served to capture the first impressions of the moderator and the assistant and to clear their minds prior to the next focus group meeting (Krueger, 1993). In addition, the PI engaged in follow-up meetings after each focus group with the methods expert associated with this study.

\section{Data Analysis}

Data collection and analysis occurred in tandem with further, more in-depth analysis occurring after data collection concluded. Data analysis was conducted using thematic analysis. Thematic analysis involved three major phases - Transcription, Mechanical, and Interpretation (Knodel, 1993).

In the first phase, transcription, the principal investigator transcribed all audio files and field notes into word processor files. Transcriptions from each focus group were stored in separate files. File names and meta-data included the date of the session and an assigned focus group number. Each word processor file was a transcript of each focus 
group. All focus group transcripts were read to verify accuracy and completeness. The audio files were played and re-played while reading the transcriptions (Knodel, 1993) to verify the correctness of the typed text. Reading the transcripts multiple times forced the principal investigator to become familiar with the data and aided in analysis (Marshall \& Rossman, 1999).

Once data were accurately transcribed, the mechanical phase began. Transcripts were read with the goal of coding data based on responses to primary questions and follow-up questions. During this step the code dictionary was generated. The code dictionary contained definitions of codes and an example emic quote and etic description for each code in order to represent analytical thinking within the analysis phase. During the next reading of the transcripts the principal investigator made notes of potential patterns and trends. Strongly held opinions and frequently held opinions were noted. During the next read, the principal investigator marked participant comments that clearly highlighted specific codes and that could be used to illustrate points in the presentation of data. Following Knodel's recommendations (1993), all data were coded, placed into general themes, and then categorized. Using an open coding technique, data were read and re-read and considered for relevance to the research questions. Those deemed relevant to the research questions were highlighted and given a code closely related to the original data. Codes were clearly defined in the code dictionary and following Thorne et al. (1997), multiple-coding of data was not done. Transcripts were read and re-read until it was clear that all relevant data had been coded. After each transcript was read completely using the steps above the principal investigator prepared a brief summary statement that described the discussion of each focus group (Krueger, 1988).

The last phase in data analysis was interpretation, in which statements were interpreted inductively based on the context in which they were made. Interpretation occurred concurrently with data collection allowing for periods of data immersion followed by focus group discussions (Thorne, 1997). Data were analyzed by themes corresponding to specific questions within and across groups (Knodel, 1993). The stratified purposeful sampling design allowed the researcher to make comparisons from one group to another within a category and from one category to another (Krueger \& Casey, 2000) as well as the overarching analysis from all focus group data.

Data analysis was augmented by the use of an overview grid, which is a technique facilitating the assessment of relationships between the study variables of interest (Knodel, 1993). The overview grid for the current study had topic headings on one axis and focus group session identifiers on the other. The cells contained brief summaries of the content of the discussion for each group concerning each topic. The summaries included in the cells of the focus grid indicate the variability or consistency of discussion regarding the topic. Additional relevant information about the focus group sessions were recorded within a cell.

A chronological set of steps suggested by Krueger (1988) was used to aid in the analysis. First, the words used by participants were considered for meaning and use. This was done by way of a frequency count of responses clustered and arranged on a 
continuum in order to illustrate the degree of similarity. Next, the context was considered by assessing the tone and inflection of the responses by listening to the audio file and reading the transcripts. Next, internal consistency was considered. Participants were allowed to change their responses or reverse their opinions after interacting with others. Changes of opinions were not noted throughout any of the focus groups. Next, a summary of major ideas found in the analysis was reported to the co-principal investigator and other members of the dissertation committee. The co-principal investigator verified major ideas across focus groups. Demographic data were entered into an electronic spreadsheet and analyzed using SPSS ${ }^{\mathrm{TM}}$. Descriptive statistics were used to summarize participants' demographic characteristics. Demographic data were used to compare participant characteristics within and between focus groups. In addition, demographic data enabled comparisons of this study's participants with other research studies.

\section{Enhancing Study Quality}

Several approaches were used to ensure the quality and credibility of this study. Precautions were taken to enhance quality during the instrument development process, sampling, data collection and analysis, and oversight processes. A number of techniques to establish trustworthiness were implemented (Lincoln \& Guba, 1985).

\section{Instrument Development Process}

The demographic questionnaire adapted from questionnaires used in prior HRSA funded studies (National Sample Survey of Registered Nurses and LISTEN). The analysis from these questions was used to report findings in similar ways to funded studies. This also improved the study by making findings comparable with other studies of similar purposes and samples.

The questionnaire was developed by researchers and practitioners knowledgeable about information appraisal. The principal investigator was assisted by three committee members with expertise and experience in designing and implementing focus group research. In addition, several committee members having a great deal of experience working with nurses in the clinical setting provided input to assure that questions used were appropriate for the target audience. Attention to the number of questions, probing questions, the terminology used, and proper question sequencing assisted in decreasing threats to quality of the study (Krueger, 1993).

\section{Sampling}

The nurse educators from DCH assisted in determining the stratification used in the purposeful sampling technique. Because of their unique knowledge about the needs of individual nursing units and their role within the organization they were able to inform the principal investigator. The nurse educators shared their practice-based knowledge, 
therefore facilitating recruitment of individuals representative of the population of interest. Further, the process allowed for the researcher to maintain control of the selection process and control for confidentiality by sampling from units, not specific individuals (Krueger \& Casey, 2000). Further, the procedure encouraged participation by those most knowledgeable of the research setting and sample pool.

\section{Data Collection and Analysis}

Throughout data collection and analysis, materials related to study intentions were reviewed to assure the protocol was being followed (Lincoln \& Guba, 1985). Careful and systematic handling of the data increased quality. For instance, each focus group was treated consistently in regard to recruitment and administration. Another example is how all audio files, demographic questionnaires, and transcript files were password protected, only accessible by the principal investigator (Lincoln \& Guba, 1985).

Raw data audio files were kept and reviewed when questions arose about transcripts. This allowed for verification of statements by participants. Hypotheses and "hunches" were recorded throughout the data collection and analysis process. In addition, the use of the overview grid (Knodel, 1993) and the use of ATLAS.ti software assisted in assuring quality data analysis. Details and rationale supporting changes in data collection tools were also recorded.

A follow-up focus group was conducted to ensure validity (Lincoln \& Guba, 1985; Morgan, 2003). Participants in the final focus group represented all categories. In this group, participants were asked to discuss processes talked about in previous focus groups. The group validated the exemplar scenarios and other details. They confirmed and elaborated on the data that had been synthesized at that point.

\section{Oversight}

The study was overseen by a dissertation committee, which offered advice on critical pieces of the study such as recruitment, questionnaire development, and analysis. Sharing focus group procedures and results with colleagues is considered "one of the most effective means of ensuring quality" (Krueger, 1993, p. 84) and is considered a major advantage in the academic setting when conducting focus group studies (Krueger). Meetings with the dissertation committee occurred during proposal development and during data collection. Individual meetings between the principal investigator and individual committee members took place throughout the study to further guide the development of the semi-structured interview guide and to assist in data collection and data analysis. 


\section{Human Studies Protection}

Permission to conduct this study was solicited from The University of Tennessee Health Science Center (UTHSC) Institutional Review Board (IRB), The University of Alabama (UA) IRB, and the DCH IRB prior to implementation. The UTHSC IRB initially approved the study in December 2010. UA and DCH IRB approval and subsequent approval was granted January 2011 and February 2011 (Appendix F).

The principal investigator obtained informed consent was obtained from each participant prior to the focus group. Information about the purpose of the study, information about how the focus group would be conducted, approximate length of time of each focus group, potential benefits of participation in the study, as well as confidentiality issues were addressed. The consent form also stated that participation was strictly voluntary and that participation would not affect employment in any way. Included in the consent form was a request for all participants to maintain confidentiality of the information discussed in the focus group.

Participants were assigned an alpha-numeric code that corresponded with the focus group number and date of focus group. The principal investigator was responsible for handling and storing all study data. Only de-identified data was shared with the principal investigator's dissertation committee for purposes of analysis. Individual participants have not been identified in any presentations or publications based on the results of the research study. Audiotapes obtained during interviews were destroyed once analysis concluded.

\section{Potential Risks to the Participant}

Risks associated with the study included uncomfortable or troublesome feelings or emotions when completing the questionnaire or focus group questions, however, the participant could choose not to answer any questions at any time. Additionally, there was a potential risk of loss of confidentiality as audio recordings are transcribed. Every effort was made to keep the personal information of each participant confidential.

\section{Potential Benefits to the Participant and Society}

Participants received a $\$ 25$ incentive for their time expended in attending the focus groups; otherwise no potential benefits were received as a result of participating in this project. General benefits to society included the advancement of science in the areas of applied information appraisal and applied information literacy within the nursing discipline and in clinical settings. 


\section{Summary}

This study used a qualitative interpretive description design to answer two research questions: What is information appraisal in the clinical setting? and How do

nurses perform information appraisal within the clinical setting? Data were collected via focus groups with 44 nurses attending one of 7 focus groups offered. Best practices in interpretive description research were utilized in the methodology to ensure greater transferability of findings to other settings. 


\section{CHAPTER 4. RESULTS}

The purpose of this study was to describe nurses' information appraisal within the clinical setting. This chapter presents the research results. The researcher collected, analyzed, and described qualitative data collected using focus groups comprised of practicing nurses in a clinical setting. Results are reported based on the answers to two research questions: 1) What is information appraisal in the clinical setting? and 2) How do nurses perform information appraisal in the clinical setting?

When interviewing the participants the term "information evaluation" was used in lieu of "information appraisal." It was believed that nurses would more clearly understand the term "information evaluation" thereby facilitating the discussion about the topic.

\section{Research Question 1: What Is Information Appraisal in the Clinical Setting?}

Participants defined information appraisal and offered examples of how they personally evaluated information in clinical situations where they needed additional information to provide patient care. Based on the descriptions offered by participants, information appraisal contains three dimensions: information gathering, information analysis, and information application.

\section{Three Dimensions of Information Appraisal}

Information appraisal was described by the participants as an iterative process of gathering the appropriate information for analysis to determine if it should be applied in a specific patient care situation. Information described by the participants included patient data found in the healthcare setting, situation-specific information, or information found through a hospital approved resource sought as a result of a perceived void in their knowledge base. During the information appraisal process, information is gathered choosing one or more possible resource options, analyzed by exploring and corroborating evidence from trustworthy, verifiable, or known resources while also considering the context, and applied within the clinical setting.

Information Gathering. Information gathering was a term used by many participants in describing information appraisal. The two terms, "information evaluation" and "gathering information" were seen as synonymous by many participants. For participants, information gathering describes the collection of information from one of three types of information resources. One participant described information appraisal this way: "gathering information and making sure you have the correct information." Participants also described using various information gathering methods to collect information. One participant described it as: "incorporating everything you're hearing, you're seeing, and using it to give the best care and improve the health of your patient." 
Other participants spoke of determining what information was needed while others described the information gathering dimension as a way to help address a void in their knowledge base. One participant described information appraisal as: "Increasing your knowledge base with trustworthy, verifiable sources."

Information Analysis. Participants also described information appraisal as asking pertinent questions, determining if information should be trusted, incorporating information from various resources, and getting answers to questions. In some cases, participants described finding validation of information from additional resources, such as websites containing similar or exact information. This helped them confirm that the information was accurate. Some participants described information appraisal as corroborating evidence or looking to known sources. They also discussed considering the context or relevance that the information may have to a situation. One participant described information appraisal as: “... adapting it [information] to the situation you're in for what you're looking for."

In some cases, verifying information resulted in making a decision to use the information or apply it in the clinical setting. Participants discussed verification of information as part of information appraisal. One participant stated: “...it's verifying new things that are not completely understood and you verify them to make sure that it's correct."

Another participant simply described information appraisal as: “... whether or not you trust that information."

Information Application. The information application dimension of information appraisal was evident in some participants' descriptions of information appraisal. One participant clearly described the interconnected nature of information appraisal and information application: "Looking for results from what I've done based on protocols and patient response to what I've done and looking at clinical values, BP, etc. and whether or not that particular drip made a difference."

In this study, there was no explicit use of the term critical reflection or critical thinking. However, one participant described information appraisal as follows: "I think it's how I acquire knowledge, internalize it, and see how it worked in that situation, and see if I'd be willing to do it again..."

\section{Influences on Information Appraisal}

Information appraisal is influenced by the specific situation, surroundings, and the personal preferences of the nurse. Different situations required different types of information. In some situations it was most efficient to discuss questions or an idea with a colleague whilst in other situations, such as policy revisions, consulting with a colleague was not appropriate. Participants explained their insistence on using evidence-based information to provide updates to policies and procedures. Participants described times 
when preferred resources were not available. For example, computer unavailability resulted in using an alternative resource such as drug book. Personal preferences were also discussed. In some cases, nurses preferred to use resources they used in nursing school such as a medical-surgical textbook or a resource that has been available to them for many years such as a Taber's Cyclopedic Medical Dictionary. These influences suggest that there is no "one size fits all" in regard to information appraisal.

\section{Consistencies in Information Appraisal}

There were consistencies in participants' descriptions of information appraisal. Participants often struggled with how to articulate their understanding of information appraisal. Many participants stated that information appraisal was information gathering. In fact, this was stated from at least one participant in six out of seven focus groups. Participants also clearly described information appraisal as a process. Their descriptions as a whole concluded that the process is iterative and for some it was considered an integral part of their daily practices.

\section{Variability in Participants' Descriptions of Information Appraisal}

Participants varied in terms of their individual opinions expressed about information appraisal. In all focus groups a consensus was lacking in terms of describing information appraisal. When discussing what information appraisal means participants usually only described one dimension: gathering, analyzing, or applying. Despite the variations in descriptions Participants did not challenge each other in their descriptions of information appraisal. Although additional ideas may have been added throughout the group discussion views were not opposed within groups.

\section{Summary}

Participants lacked a unified definition of information appraisal. They often spoke about information gathering or information application activities when defining information appraisal. Participants' comments indicated that they did not consider information appraisal as an independent activity when working with acquired information.

Resources accessed varied among participants and the unique situation at hand. Their collective descriptions concluded that information appraisal is multi-dimensional and performed at the individual level. Though the process itself is performed at the individual level and variations do exist, commonalities were seen as of participants' described their experiences. 


\section{Research Question 2: How Do Nurses Perform Information Appraisal in the Clinical Setting?}

The information appraisal process described usually began with a question, prompt, or need to verify information, proceeded to finding the information through a number of possible resources, and ended once the nurse received the information from a trusted resource. Resources used in all situations described by participants fell into one of three categories: human information resources, electronic information resources, or print information resources.

To begin their descriptions of information appraisal in the clinical setting, participants were asked to share a story about a time in which they needed more information to care for a patient. Most stories shared by the participants centered on uncertain moments and/or an unfamiliar situation. All participants were able to clearly describe a situation in which they perceived a void in information. Most were able to offer details about what prompted their need for information, how they acquired new information, how they evaluated the information, and rules or guidelines they used when evaluating information. Similar situations often yielded similar patterns in the information appraisal process among nurses but in most cases the process was influenced by personal preference.

\section{Trusted Resources}

Nurses perform information appraisal in the clinical setting by way of an unspoken algorithm with two major decision points. First, nurses determine the urgency of the situation. Next, they select the resource of choice based on the urgency of the situation and their a priori knowledge of available resources, not the content provided by the resource. There were some instances when nurses evaluated and trusted the content provided by the resource. However, in most cases, the trusted resource served as a proxy for evaluating the information that was provided by the resource.

\section{Types of Situations}

Participants described several types of situations that prompted them to look for, evaluate, and apply information. Although the details of each situation were highly unique, they could be divided into urgent or non-urgent situations.

Urgent Situations. Participants' descriptions varied based on their perceptions of the situational urgency. Urgent type situations were time sensitive and usually involved a critical or deteriorating patient. Examples included patients presenting with cardiac distress, pregnant trauma patients, and acute stroke patients.

Participants commonly reported turning to human information resources in urgent situations. Human information resources that nurses turned to in urgent situations 
included physicians, nurses with specialty area experience, nurse managers, house supervisors, or someone in a highly distinguished professional role, such as a nurse manager. These resources were chosen based on their experience, credentials, reputation/credibility, professional role or designations, or role in a specialty area. Little conversation or elaboration was offered further than this when participants described urgent types situations. The following is an example of an urgent situation: "...he was an alcoholic but he came in with pancreatitis and esophageal varices... after I was doing his assessment he just started vomiting, well he started doing like this [holding neck with hands], and I'm looking and I'm like "are you choking?" And he starts doing like this [holding neck with hands] and he was trying to get up and I end up doing the Heimlich and he had this big blood clot come out, and his throat just started bleeding..."

Non-Urgent Situations. Non-urgent situations were those where more information was needed, however, there was more time for accessing and evaluating additional information. Non-urgent situations predominantly described by participants involved situations characterized by unfamiliarity. These situations included unfamiliarity with a culture or language, procedures, equipment, diagnoses, age range, patient care situations, or medication questions. The following is an example of a nonurgent situation: “... we had a young lady, 21, had porphyria... I had no idea what it was... I needed to know what were some things, what was the disease process, what it did to her, how she ended up like this, what were some things we could do to teach her to be more compliant, find out why she was non-compliant to begin with and just to help her deal with being in the ICU because she was 21 years old..."

Information resource selection is affected by the urgency of the situation encountered by a nurse. Urgent situations demand instantaneous information that nurses seek from each other or other members of the healthcare team. Non-urgent situations are less pressing than urgent ones and allow for additional time to be spent selecting and evaluating information. Participants described using a variety of resources in non-urgent situations.

\section{Types of Information Resources}

Participants report finding information in one of three formats: human information resources, electronic information resources and print information resources. Human information resources included co-workers including nurse colleagues, physicians, and pharmacists. Participants frequently described the use of hospital approved electronic resources including Micromedex, Up-To-Date, Krames, and the EMar as an information resources. They also discussed using WebMD and search engines such as Google. Print resources were referenced by participants. Print resources included textbooks or print references that could be accessed within the clinical setting.

Human Information Resources. Human information resources were people, typically co-workers, which participants would use as an information resource when 
participants needed information in some situations. Examples of human information resources included other nurses, staff, physicians, and pharmacists. Human information resources were evaluated subjectively by nurses needing information. Participants reported weighing decisions to use information from another person based on the past professional experience of and/or with the co-worker, the professional role or position of the co-worker, coworker reputation or credibility, and/or coworker specialty area experience. Human information resources were most often used when a situation was urgent and information was needed in a timely manner or when a particular level of expertise was sought.

Participants described seeking information from nurses that they knew had longevity in the discipline. Participants described trusting those that had worked at the hospital or other places. More experienced nurses were identified by participants as having been in their position for several years, were often assigned the role of charge nurse, and had been in different patient care environments. One participant stated: "I will go to the veterans on my floor. The ones that have worked here and, you know, other hospitals and who have done a lot..." Some nurses would seek more experienced nurses to ask them their opinions about where to look for more information: "I know in the past when I hadn't really known which site to go to I've asked the older, more experienced nurses, ok, where do you go look things up? I think it's invaluable, you know, people that have worked in that area or that have been a nurse longer."

Participants discussed considering their co-workers' reputations when deciding whether or not to trust information from them. If co-workers were known for work they have done with their patients and had not been involved in many mistakes, participants trusted the information they provided. Participants would not seek information from those that had been known to make errors in regard to patient care in the past: "their [coworker's] reputation as a nurse, if they have made a whole bunch of mistakes in the past."

Participants described seeking information from nurses with specialty area experience. They sought information from these resources when they were caring for a patient that had been receiving specialty care such as a cardiac or oncology situation. One participant described a situation where her patient was receiving chemotherapy. The participant did not know if she would be able to administer a medication and called for help from the oncology unit: "We had an orthopedic patient ... they had been on some chemo drugs ... they ordered a medication that we had never heard of and did not know if we had to be certified to give that medication. So we had to call the nurse manager on the cancer floor and she actually came up and gave the medicine." Another nurse described needing to seek information from someone in a cardiac unit about an electrocardiogram: "I use people with more experience. And it doesn't necessarily have to be people on my unit. If I have a cardiac strip that I am not really sure about I go to ACCU [Acute Cardiac Care Unit] and have a nurse look, you know, use your coworkers." 
In other situations, participants looked to nurses that were considered experts because of their knowledge in a specific area. These "experts" were known for their reputation and professional role. One participant from a critical care environment described seeking out "expert nurses": "I think we all just go to the experts because whenever we get a pregnant trauma our first call is up there to you guys. Excuse me, I think the baby might not have heart tones. I need you to come check this out for us...It's not just within your unit. You also have to reach out to areas of the hospital hoping to draw on their areas of expertise."

Participants described trusting a human information resource as often being related to past experience with the resource. For example, participants often discussed turning to a co-worker with experience. They described considering the reputation, past experience, and longevity of the co-worker in the clinical setting: "In trusting the older staff, in my case, I had just observed them in situations before that I felt like lend credibility to their actions."

Physicians were commonly named as information resources in situations where the nurse had questions about the diagnosis. Physicians were sought as resources of information because of their role and presumed knowledge. For example, one nurse stated: "I felt very confident that Dr. XXXXXX knew his business as he was the head of the Cancer Unit and I just felt like he was very reliable so I respect him and his knowledge and stuff like that and he knew what he was talking about." Another nurse commented that she felt confident about talking with the physician about an unfamiliar medication she was administering to a patient that had recently suffered a stroke: "The physician was there and I felt confident because I knew he was certified in this area and he was bringing his certification with him to open this acute stroke unit so I was very confident in what he was there to, just to answer whatever questions I had."

Several participants commented that they turned to other nurses to collect baseline or cursory information about a medication. Those that chose this as a first line option also talked about using a "back-up" to collect additional information about the medication such as side effects or dosage information. For instance, one participant stated: "I think I would have to have back up too ... something in writing that said, verified that information." The exception to asking another nurse was when they talked with a pharmacist. In that case they did not talk about having a "back-up," which would be in the form of an electronic or print resource.

Electronic Information Resources. Electronic information resources were those found in computerized format. These resources included those available on the hospital intranet, online websites, or information found through a personal digital assistant. In some cases, participants identified specific sources. Participants discussed Internet sites such as WebMD or hospital approved electronic resources such as Micromedex or UpTo-Date, from where they would gather information. 
Electronic information resources were cited as a source for information in a number of situations but most commonly as a resource for medication information. Hospital approved electronic resources were those made available to nurses through the hospital intranet and were the most commonly cited electronic information resources. When using online hospital approved resources it was clearly articulated that participants trusted them and did not question them further. For example, one participant said: "I guess because I know the hospital put it there for that reason and there were people that had evaluated those sites instead of just going basic Internet because a lot of that information isn't always reliable so I felt comfortable going with what the hospital had put in place."

Electronic information resources were evaluated based on their reliability as determined from prior use. One participant described the idea of reliability in an online hospital approved resource: "You just use it over and over again. You feel comfortable because it's never let you down."

Some participants described using trusted websites. One participant explained her thoughts on trusting websites: "I remember when I was in school they had us do like WebMD was a big one, you could trust it because it had certifications, you scroll to the bottom and it had all these supported by or endorsed by or something like that... if I'm looking for like a simple definition, then it's always Wikipedia which I know I probably shouldn't trust at all."

WebMD was mentioned several times throughout the focus groups as an electronic resource used to find more information. One participant said: "Isn't WebMD NIH or something like that? It's from the government then hopefully it's pretty accurate."

Participants sometimes reported going to several websites or online resources to find information. They discussed that validating information online made them feel comfortable with using it: "when you go to a lot of sites and they are telling you the exact same information and they are saying it's based on evidence."

Print Information Resources. Print information resources were cited as a resource by some participants and were defined as being information resources found in a hardcopy of a research article or reference book. Examples of print resources included journal articles, reference books, and textbooks. Participants described evaluating these resources based on their status as a designated text or reference book in nursing school. In some cases, participants spoke of looking at the currency or date of the resource. Some participants mentioned the reputation of specific books as a means of evaluating them. For example, one person said: "There seems to be a matter of trust. You have to trust your information like Taber's or Mosby's. You know these books have been around. Millions of people have used these books for the exact same thing, looking up information., So you have to be able to trust that these millions of people have used the books, that the book is giving reliable information..." 
Medication type questions were often considered non- urgent and were often specifically reported as needing more information on drug action, dosage, or side effects. These situations often allowed for more flexibility and time for accessing and evaluating resources.

Print resources, such as drug books, were evaluated based on currency and were often used if they had been designated books or resources for the participant while in nursing school. Print resources were evaluated the same way in which electronic resources were evaluated. The main difference in selecting print or electronic information resources seemed to be related to availability.

Print resources such as journal articles or textbooks were frequently cited when participants discussed updating policy and procedures. Participants talked about gathering resources comprehensively when updating a policy. The use of humans as information resources when updating policies and procedures was discouraged. Participants discussed resources used to update policies and procedures as needing to be referenced, reputable, and based on evidence. One participant stated: “...you want to get everything, the most up-to-date evidence based best practice as you possibly can. And that's not going to come from word of mouth from another nurse somewhere, that's going to come from the research based evidence that is out there. " One participant stated she would have to determine the level of evidence when using information to update a policy: "...I would have to grade the evidence. "Another participant said they did not question articles in journals because: "I don't typically question them because the way I look at it is if is in a journal then it's going to be reviewed by lots of people before it gets put in there."

\section{Is It Safe and Logical?: Other Criteria Used to Evaluate Information}

There were additional criteria used by participants to help determine if they would use information. These included questioning the safety of a new intervention or asking if the information is logical or finding the rationale.

On several occasions participants mentioned asking about the safety of a new intervention or information to be used in the clinical setting. In fact, one participant shared that she simply asks when evaluating information that might be used in patient care: "Is it safe? Is it going to harm anybody?" Another participant stated: "... if it seems bizarre, then surely you will go somewhere else and double check what you are reading before you go and apply it to a patient."

Logic or discovering the rationale was also mentioned. Knowing the reason behind the intervention or change in procedure helped the participant to understand and feel more comfortable about using the information. One participant described her comfort in finding and discussing the rationale behind a change in procedure: "I'm old school enough that I have to understand why or how is this going to help my patient before I can go in and talk to them about it ... So we get this patient in and they have croup so the resident writes for a croup tent, ... I would come back and it would be gone so the third night I asked the resident for the croup tent and the resident said 'Oh no, you cannot 
have a croup tent... Well, then when she told me what the new research was and why it had been proven not to be as effective as maybe something else would be I was like OK, kind of like the light bulb thing. Once you understand it you can buy into it, and sell it."

Participants talked about being uncertain when faced with new procedures. One example was that of an OR nurse needing more information on how to correctly label a specimen for the lab. Another example was that of a critical care nurse needing more direction on using urokinase to de-clot a ventriculostomy: "We actually got a patient with a severe intracranial hemorrhage and is was so severe we were on her third ventriculostomy, she kept clotting them off. And what physician and the neurosurgeon wanted to inject her ventriculostomy with urokinase. We had never heard of it, have never done it, had no idea, didn't know about the medicine, didn't know how to do it, didn't know what would happen to her if we did it. I didn't know where to start. None of us had ever done it. So I called him [physician] back." In cases such as this where nurses needed more information they turned to human information resources.

\section{Accessibility of Information}

Accessibility of information resources was discussed within focus groups. Participants often described having to use available resources available instead of a preferred resource. In some cases the preferred resource was not available, causing the nurse to turn to an alternative format of information. Focus group members discussed preferring an online drug reference but not having an accessible computer. Others discussed preferring to talk with a specific person or an "expert" but the person not being available when they needed them and therefore turned to an alternate information resource. One participant talked specifically about needing an answer to a breastfeeding patient's specific question about a drug: “...the lactation person wasn't there so I ended up asking one of the other RNs to see if they had the experience or patients and they go like 'no' so I actually just ended up looking online."

\section{Differences between Focus Groups}

In analysis, it was determined that there was no difference between the groups' descriptions or explanations offered in response to the interview questions. In the planning stages of the project, it was thought that the nurse educators' ranking system (based on unit involvement in educational offerings, pilot unit status, inquiries from nursing staff and nurse managers) would yield differences in the responses. Ultimately, there were no differences manifesting between the units in terms of the amount or depth of discussion about information appraisal. In hindsight, it was determined that the nurse educators' ranking system primarily served as a proxy for unit participation in this study, and therefore was very helpful in forecasting and planning focus groups. 


\section{Summary}

The results of this research indicated that information appraisal within the clinical setting is an iterative process of gathering appropriate information in order to analyze and determine if information will be applied to a situation. The process begins with a determination of the urgency of the situation. During urgent situations nurses are most likely to seek information from an "informed" person. In non-urgent situations, information was sought in a number of formats (print, electronic, human information resource). Information resource selection is influenced by the type of information sought, preferences, accessibility, and the situation at hand. Information shared among coworkers may be verified as "back-up information" using credible resources. Results gained from this study should be used to offer suggestions for further research, which will be offered in the subsequent chapter. 


\section{CHAPTER 5. DISCUSSION}

\section{Introduction}

The purpose of this study was to define and describe the process of information appraisal by nurses in the clinical setting. The focus group participants described information appraisal and shared examples of how they performed information appraisal in the clinical setting. Participants in this study also described situations in which they needed more information to care for their patients. They elaborated on where they sought information, how they found it, and why they trusted certain information. They also discussed rules and guidelines used when applying information in patient care. In many cases, participants often sought co-worker advice or electronic or print resources.

A summary of the findings and discussion of study implications for nursing practice and education are found in this chapter. The chapter concludes with suggestions for future research and limitations.

\section{Summary of Results}

Participants described information appraisal as a process of information gathering, information analysis, and information application. However, there was variation in the descriptions offered by participants and some participants had trouble describing information appraisal in the clinical setting. Results from this study suggest that nurses do not know about or discern between the different information literacy phases documented in the literature. In particular, the participants did not see information appraisal as a separate and distinct step within the information literacy process. This was evidenced by the most common descriptions of information appraisal, which characterized the process as that of "information gathering." Contrary to traditional definitions of information appraisal, participants usually described only one of three dimensions of information appraisal: information gathering, information analysis, or information application.

Information appraisal was described by the participants as an iterative process of gathering the appropriate information for analysis to determine if it should be applied in the patient care setting. These information resources include patient data stored in the healthcare setting or situation-specific literature they may seek as a result of a perceived void in their knowledge base. During the information appraisal process, information is analyzed by exploring and corroborating evidence from trustworthy, verifiable, or known resources while also considering the context. In some cases, verifying information resulted in making a decision to use the information or apply it in the clinical setting. The information appraisal process is influenced by the urgency of the specific situation, surroundings, and the personal preferences of the nurse.

Participants described instances where they needed more information, which included how they located the information and in what format they found it. Responses indicated that participants were using information resources as proxies for evaluating 
information found in the clinical setting. In most cases, participants reported feelings of comfort regarding the resource and did not always talk about evaluating the information provided by the resource. Participants had few rules and guidelines they could articulate for determining if they should use the information in their care for patients. This lack of elaboration about rules and guidelines suggested that participants do not employ them in the information appraisal process.

Nurses perform information appraisal in the clinical setting by way of an unspoken algorithm with two major decision points. First, nurses determine the urgency of the situation. Second, they combine their perceptions of situational urgency with their prior knowledge of available information resources to select a resource. Perceptions about a source of information were often used to indicate the specific information that source provides.

Study participants also reported seeking additional information when they were not certain about a situation. Unfamiliar or new situations were the most frequent prompt for seeking more information. Examples of unfamiliar or new situations included unfamiliar diagnoses, medications not previously administered or not allowed (e.g., to a specific age group), and unfamiliar procedures. The majority of participants reported medication questions and questions about unfamiliar diagnoses prompted them to seek additional information. This is consistent with the study finding that routine activities and tasks in the clinical setting were generally not questioned by participants.

Throughout the progression of the focus groups, there was no expressed "one size fits all" when proceeding through the information appraisal process. Each patient care situation was influenced by many factors, including patient situations, information needs, nursing unit resources, professional experience, and educational background. Because of the various factors in each sitauion there was not a precise pattern nurses followed in gathering and evaluating information. In addition, there was no single resource that nurses would turn to for answers to their questions.

\section{Implications for Practice}

\section{Collegial Collaboration}

This section describes how answers to the research questions may influence prevailing understandings about nursing practice. The results of a survey used to collect data about the self-perceived information seeking skills and tools of nurses indicated that nurses in the U. S. were not ready for evidence-based practice (Pravikoff, Tanner, \& Pierce, 2006) In this study nurses' most frequent source of information was a peer or colleague This is noteworthy considering colleagues often provide information on traditional practices and may not offer the most up-to-date information. The results of the current study gave insight into the value of colleagues during urgent clinical situations, when there are otherwise limited sources of information. However, more must be 
understood about the sharing and use of nurse colleague-based information within the clinical setting.

Focus group participants discussed the dependence they have on co-workers regardless of the urgency of the situation. In urgent situations, co-workers were viewed as helpful and valuable information resources. In non-urgent situations, there was also a strong reliance on obtaining information from co-workers. These results parallel other studies whose authors found that nurses voice their preferences in obtaining information from experience and interactions with co-workers rather than journals and texts (Estabrooks, et al., 2005; Gerrish et al., 2011).

The results from this study echoed Rycroft-Malone et al.'s (2004) argument that evidence does not always come in the form of a research article or scientific study results. Rycroft-Malone et al. suggest four types of evidence in the delivery of care: patient experiences, clinical experiences, local context, and research. It was apparent that in most cases, nurses did not turn to research-based articles or scientific study results for information. Instead, they sought information from the clinical setting, patients, and coworkers. More must be understood about the integration of all types of information resources in an effort to provide high quality care. Most evidence-based care studies focus on using research-based evidence in the clinical setting. Other forms of evidence are not discussed in the literature leaving the possibility for personal interpretation and judgment of nurses in the clinical setting.

When describing seeking information from co-workers, participants described looking to those having a particular level and specialty of experience, interdisciplinary knowledge, or certifications or credentials. For example, in the case of technology, some nurses preferred speaking with new nurses as the result of the presumed recent exposures of these new nurses to tools and advances related to information of which more experienced nurses were not aware. In other instances, such as caring for a deteriorating patient, a more experienced nurse was preferred. Specific genres of experience were preferred in some cases to assist with specialized assessments. For example, if a patent was admitted to a medical intensive care unit and was found to be pregnant, nurses would seek advice and counsel from an experienced obstetric nurse about the immediate patient care needs. Furthermore, interdisciplinary involvement was valued when nurses needed more information. For example, when administering a medication, nurses often sought the guidance or counsel of a pharmacist. Participants reported that in some cases, knowing the credentials of some healthcare providers made them feel more comfortable using the information. In these types of situations, information provided was typically taken at face value and not questioned further.

Results from this study also suggest that nurses place a higher value on certifications and credentials of the people from whom they receive information. In many cases, participants described feeling comfortable talking with someone they knew who had a special certification or credential and as a result, having knowledge contributing positively to nursing situations. In addition, several participants spoke of turning to someone with specialty area experience (e.g., oncology or high-risk obstetrics) when 
encountering unfamiliar patient circumstances. The above instances suggest that "expert nurse" consulting is a valuable concept and may be viewed as an efficient resource by clinical nurses. Nurse educators should also consider preparing nurses to have specialty roles, such as Clinical Nurse Leaders (CNLs) and credentials to increase the population of expert nurses within specific domains of care. At this time, the nursing discipline does not routinely promote the consultation of expert nurses as part of routine inpatient care.

\section{Information Resource Preferences}

The focus groups provided evidence that information appraisal is an individualized and unpredictable process. Information appraisal behavior is based on one's comfort with the situation, experience, available resources, and preferences. Some participants commented that they chose resources often based on habit, familiarity, and preference. In most cases nurses in the current study spoke less about appraising the content or information provided by resources but instead described their judgment about the resource they were using.

It can be inferred from this study that more experienced nurses are seeking evidence less and may not be basing their practice on the most current information. Participants reporting having been in their position for some time said they believed they had fewer questions than newer nurses. Some newer nurses participants reported turning to more experienced nurses for answers to questions. Their stated reason for doing so was their perceived comfort with the information provided by more experienced professionals.

Patient centered care emphasizes the preferences and individuality of the patient. Variations in perceptions about information appraisal could possibly result in inconsistencies in the application of evidence-based information in practice. Based on this research, the preferences and needs of the nurse will also influence patient centered care.

Print and electronic resources were used in non-urgent situations by focus group participants. It was assumed that if the hospital provided the resource, it was meant to be used for professional purposes and was trusted and reliable. Again, familiarity, habit, and preferences influenced the type of resource used by nurses. These results may reflect perceptions regarding nurses' attitudes towards information resources. Scott \& Pollock (2008) concluded that unit culture perceived by nurses influence attitudes toward information resources. In that study, nurses were not expected to base their practices on research they acquired and believed it was someone else's responsibility to tell them what to do. More must be explored related to the types of information resources that are useful in the clinical setting. Information resources provided to nurses by healthcare organizations vary greatly and additional research is needed to develop a minimum set of information resources that health care facilities should provide nurses.

Instinct was discussed a number of times, as participants described how they evaluate information. Using instinct as a resource when determining what is right for a 
patient is not new to nursing. Gerrish et al. (2011) surveyed 811 nurses in the UK asking them to rate the frequency that they used particular sources of evidence. Their survey found that $33 \%$ of the participants frequently/always used intuition as a source of evidence.

\section{Care Delivery}

Most professional nursing education programs have included courses in nursing research but often neglect the more meaningful and pragmatic quests of clinical scholarship. As healthcare changes and inpatient acuity increases nurses are often faced with prioritizing care and have little time to seek, evaluate, and apply information that provides answers to their questions. White \& Taylor (2002) questioned the feasibility of a care model including nurses providing direct patient care in addition to the roles of independently seeking, appraising, and applying research evidence. They reported that these additional roles were so time consuming that should practicing nurses engage in them, they would not meet their clinical obligations. Nurses in leadership positions such as such as managers, CNLs, and care coordinators may play a vital role in disseminating knowledge to nurses and other members of the healthcare team (American Association of Colleges of Nursing, 2007).

As patient care shifts to the outpatient and community setting through healthcare reform, information appraisal must once again be considered. Without the resources readily available to nurses providing care in an inpatient setting information appraisal becomes very important. Where will nurses seek information and how will they be evaluation information provided? Equipping nurses to evaluate information in a variety of care contexts will help prepare them to care for patients in the future (O'Neil, 2009).

\section{Implications for Nursing Education}

Exposure to information appraisal or information literacy skills, whether in a formal educational or clinical setting, does not guarantee proficiency (Hebda \& Czar, 2010). Further investigation is necessary to learn more about educational strategies and measuring competencies for information appraisal.

Nurses are rarely provided with a formal education regarding information appraisal. Programs focusing on information appraisal in nursing have focused primarily on "critical appraisal," which deals with evaluating research-based literature. Given the expansion of the information society and the variation of information resources, nurses must evaluate information of all types. Educational programs or courses focused on how to evaluate information such as patient experiences, clinical experiences, information from the local context, and research-based information encountered in the clinical setting should be offered. Teaching nurses where to go for information and how to evaluate its trustworthiness could prove to be beneficial in the clinical setting. 
Nursing education must prepare nurses for the information society by teaching and developing methods for evaluating resources of all types - not just research-based resources. By knowing when to use certain types of information, more efficient, competent, and confident care can be provided. More research needs to be conducted to support policies allowing time for nurses to engage in seeking, evaluating, and applying information in the clinical setting.

Several organizations such as the Technology Informatics Guiding Education Reform (TIGER) and Quality and Safety Education for Nurses (QSEN) have developed competencies that guide nurse educators teaching students how to use information and technology to communicate, manage knowledge, mitigate error, and support decision making (QSEN). However, informatics competencies focus on applying technology and information management tools, not appraising information. Subsequently, findings from this study may influence expansion of nursing informatics competencies to include situated information appraisal competencies required in clinical nursing practice.

Study findings also suggest the importance of critical thinking skills in information use. In an effort to overcome the deficiencies in an information age that requires nurses to evaluate the quality and accuracy of information stored for later use critical thinking skills are crucial. Nursing faculty must strive to promote critical thinking skills in nursing students that will allow them to evaluate information that comes to them in multiple formats while working in various patient care settings.

\section{Recommendations for Future Research}

The results of this research provide a foundation and background for future research in the area of information appraisal. Information appraisal by nurses in the clinical setting needs further investigation to examine the influence of using designated "trusted resources" within the clinical setting. Nurses discussed using resources in which they had previous experience using. More needs to be understood about the characteristics and vetting of trusted resources. Studies that explore why nurses reject or ignore certain types of information are also needed.

Participants spoke of not turning to specific types of information in certain situations. For instance, it was clear that nurses looked to research-based or scientific studies when updating or creating policies and procedures. Understanding more about why nurses may choose to not incorporate certain forms of acquired information in their decision-making will build on understandings of information appraisal.

Research on educational intervention and training program strategies for promoting evaluation of multiple types of information formats used by nurses is also needed. Comparison studies are needed to explore the differences and consistencies in patient outcomes when trusted versus un-trusted information is used during information appraisal by nurses. 


\section{Limitations}

This study has several limitations. First, the stratified non-random sample represents mostly (93\%) female nurses from one hospital in the southeastern United States and does not necessarily represent nurses everywhere. This limitation means that the study findings may not be easily transferable to other health care settings. Second, there were fewer participants within the lower stratum of the study and the number of participants within each stratum was not equal. All eligible inpatient units were not represented. Of the twenty units eligible for participation in the study, four units did not have representation. Personal and professional schedules kept some nurses from participating. Scheduling conflicts were thought to have affected unit representation.

\section{Summary}

This study attempted to address the gap between nursing literature and practice. The researcher found that nurses do not generally seek literature or evidence-based sources to answer day-to-day questions. Instead nurses most often use other forms of information within the clinical setting. In addition, nurses do not appraise content found within information resources used in the clinical setting. Rather, nurses' evaluations are

of the information resource, which serves as a proxy for appraising the information being provided.

The study has several implications for nurses in both practical and academic settings, especially in an era of dynamic change caused by the information revolution. Variations in clinical nursing practice can cause great inconsistency in decision making and healthcare outcomes. The results should also inform nurse educators of the complexities regarding nurses' information need in the clinical setting. Understanding these complexities may help guide the development of programs for enhancing information appraisal in the clinical setting. These results point to future research and theoretical advancement, especially on how nurses specifically perform information appraisal and what they consider to be useful information. 


\section{LIST OF REFERENCES}

Alpay, L., \& Russell, A. (2002). IT training in primary care: The nurses' voice. CIN: Computers, Informatics, Nursing, 20, 136-142.

American Nurses Association. (2008). Nursing informatics: Scope and standards of practice. Silver Spring, MD: Nurses Books.

Association of College \& Research Libraries. (2011). Information literacy competency standards for higher education. Retrieved September 6, 2011, from http://www.ala.org/ala/mgrps/divs/acrl/standards/informationliteracycompetency. $\underline{\mathrm{cfm}}$

Banning, M. (2005). Conceptions of evidence, evidence-based medicine, evidence-based practice and their use in nursing: independent nurse prescibers' views. Journal of Clinical Nursing, 14(4), 411-417.

Barnard, A., Nash, R., \& O'Brien, M. (2005). Information literacy: Developing lifelong skills through nursing education. Journal of Nursing Education, 44(11), 505-510.

Berland, G., Elliott, M., Morales, L., Algazy, J., Kravitz, R., Broder, M., . . McGlynn, E. (2001). Health information on the Internet: Accessibility, quality, and readability in English and Spanish. Journal of American Medical Association, 285(20), 26122638

Bernardo, L., Mathhews, J., Kaufmann, J., \& Yang, K. (2008). Promoting critical appraisal of the research literature: A workshop for school nurses. The Journal of Continuing Education in Nursing, 39(10), 461-467.

Bickford, C., Smith, K., Ball, M., Frantz, G., Panniers, T., Newbold, S., . . CortesComerer, N. (2005). Evaluation of a nursing informatics program shows significant changes in nurses' perceptions of their knowledge of IT. Health Informatics Journal, 11(3), 225-235.

Breivik, P. (1991). Information literacy. Bulletin of the Medical Library Association, $79(2), 226-229$.

Brettle, A. (2003). Information skills training: A systematic review of the literature. Health Information and Libraries Journal, 20(Suppl. 1), 3-9.

Cader, R., Campbell, S., \& Watson, D. (2003). Criteria used by nurses to evaluate practice-related information on the World Wide Web. CIN: Computers, Informatics, Nursing, 21(2), 97-102. 
Cader, R., Campbell, S., \& Watson, D. (2009). Judging nursing information on the WWW: A theoretical understanding. Journal of Advanced Nursing, 65(9), 19161925.

Cheek, J., Gillham, D., \& Ballantyne, A. (2005). Using education to promote research dissemination in nursing. International Journal of Nursing Education Scholarship, 2(1).

Ciliska, D. (2006). Evidence-based nursing: How far have we come? What's next? Evidence Based Nursing, 38-40.

Cooper, H. (1998). Synthesizing research (3rd ed.). Thousand Oaks, CA: Sage Publications.

Courey, T., Benson-Soros, J., Deemer, R., \& Zeller, R. (2006). The missing link: Information literacy and evidence-based practice as a new challenge for nurse educators. Nursing Education Perspectives, 27(6), 320-323.

Cullen, R. (2002). In search of evidence: Family practitioners' use of the Internet for clinical information. Journal of Medical Library Association, 90(4), 370-379.

Dawes, M. (1996). On the need for evidence-based general and family practice. Evidence-based Medicine, 1, 68-69.

Dee, C., \& Stanley, E. . (2005). Information-seeking behavior of nursing students and clinical nurses: Implications for health science librarians. Journal of the Medical Library Association, 93(2), 213-222.

Dorner, J., Taylor, S., \& Hudson-Carlton, K. . (2001). Faculty-librarian collaboration for nursing information literacy: A tiered approach. Refernce Services Review, 29, 132-140.

Englebardt, S., \& Nelson, R. (2002). Health care informatics - An interdisciplinary approach. St. Louis: Mosby.

Erdley, W. (2005). Concept development of nursing information: A study of nurses working in critical care. CIN: Computers, Informatics, Nursing, 23(2), 93-99.

Estabrooks, C., Chong, H., Brigidear, K., \& Profetto-McGrath, J. (2005). Profiling Canadian nurses' preferred knowledge sources for clinical practice. Canadian Journal of Nursing Research, 37(2), 118-141.

Estabrooks, C. A., O'Leary, K. A., Ricker, K. L., \& Humphrey, C. K. (2003). The Internet \& access to evidence: How are nurses positioned? Journal of Advanced Nursing, 42(1), 73-81. 
Ford, J. S., \& Profetto-McGrath, J. (1994). A model for critical thinking within the context of curriculum as praxis. Journal of Nursing Education, 33(8), 341-344.

Fox, L. (1989). Teaching the wise use of information-evaluation skills for nursing students. Western Journal of Nursing Research, 11, 773-776.

Fox, L., Richter, J., \& White, N. (1996). A multidimensional evaluation of a nursing information-literacy program. Bulletin of the Medical Library Association, 84, 182-190.

Gerrish, K., Guillaume, L., Kirshbaum, M., McDonnell, A., Tod, A., \& Nolan, M. (2011). Factors influencing the contribution of advanced practice nurses to promoting evidence-based practice among front-line nurses: Findings from a cross-sectional survey. Journal of Advanced Nursing, 67(5), 1079-1090.

Gilmour, J., Scott, S., \& Huntington, N. (2007). Nurses and Internet health information: A questionnaire survey. Journal of Advanced Nursing, 61(1), 19-28.

Gosling, A., Westbrook, J., \& Spencer, R. (2004). Nurses' use of online clinical evidence. Journal of Advanced Nursing, 47(2), 201-211.

Graves, J. R., \& Corcoran, S. (1989). The study of nursing informatics. Image, 21(4), 227-231.

Hall, A., \& Walton, G. (2004). Information overload within the health care system: A literature review. Health Information and Libraries Journal, 21, 102-108.

Hannes, K., Vandermissen, J., DeBlaeserm L., Peeters, G., Goedhuys, J., \& Aartgeers, B. (2007). Barriers to evidence-based nursing: A focus group study. Journal of Advanced Nursing, 60(2), 162-171.

Hanson, D., Hoss, B., \& Wesorick, B. (2008). Evaluating the evidence: Guidelines. AORN Journal, 88(2), 184-196.

Heater, B., Becker, A., \& Olson, R. (1988). Nursing interventions and patient outcomes: A meta-analysis of studies. Nursing Research, 37, 303-307.

Hebda, T., \& Czar, P. (2009). Handbook of informatics for nurses and healthcare professionals (4th ed.). Upper Saddle River, NJ: Pearson Prentice Hall.

Ibbotson, T., Grinshaw, J., \& Grant, A. (1998). Evaluation of a programme of workshops for promoting the teaching of critical appraisal skills. Medical Education, 32, 486491. 
Jacobs, S., Rosenfeld, P., \& Haber, J. (2003). Information literacy as the foundation for evidence-based practice in graduate nursing education: A curriculum-integrated approach. Journal of Professional Nursing, 19(5), 320-328.

Johnson, C., Lindsay, E., \& Walter, S. (2008). Learning more about they think: Information litearcy instruction in a campus-wide critical thinking project. College and Undergraduate Libraries, 15(1/2), 1-11.

Jutel, A. (2008). Beyond evidence-based nursing: Tools for practice. Journal of Nursing Management, 16, 417-421.

Katrak, P., Bialocerkowski, A., Massey-Westropp, N., Kumar, S., \& Grimmer, K. (2004). A systematic review of the content of critical appraisal tools. BMC Medical Research Methodology, 4(22), 1-11.

Kearney, M. (2001). Levels and applications of qualitative research evidence. Research in Nursing \& Health, 24, 145-153.

Knodel, J. (1993). The design and analysis of focus group studies: A practical approach. In D. Morgan (Ed.), Successful focus groups: Advancing the state of the art (pp. 35-50). Newbury Park, CA: Sage Publications.

Koehn, M., \& Lehman, K. (2007). Nurses' perceptions of evidence-based nursing practice. Journal of Advanced Nursing, 62(2), 209-215.

Krainovich-Miller, B., Haber, J., Yost, J., \& Jacobs, S. (2009). Evidence-based practice challenge: Teaching critical appraisal of systematic reviews and clinical practice guidelines to graduate students. Journal of Nursing Education, 48(4), 186-195.

Krueger, R., \& Casey, M. A. (2000). Focus grous: A practical guide for applied research. Thousand Oaks, CA: Sage Publications.

Krueger, R. A. (1993). Quality control in focus group research. In D. L. Morgan (Ed.), Successful focus groups: Advancing the state of the art. Newbury Park, CA: Sage Publications.

Krueger, R. A. (1998). Developing questions for focus groups. Thousand Oaks, CA: Sage Publications.

Ku, Y., Sheu, K., \& Kuo, Y. . (2007). Efficacy of integrating information literacy into a women's health course on information literacy for RN-BSN students. Journal of Nursing Research, 15(1), 67-76.

Land, L., Ward, S., \& Taylor, S. (2002). Developing critical appraisal skills amongst staff in a hospital trust. Nurse Education in Practice, 2, 176-180. 
LISTEN Project. (2007). About our project. Retrieved March 1, 2010, from http://listenuphealth.org/home/index.php?option=com_content\&task=view\&id=3 $\underline{0 \text { \&Itemid }=75}$

Marshall, C., \& Rossman, G. (1999). Designing qualitative research. Thousand Oaks, CA: Sage Publications.

Mcgonigle, D., \& Mastrian, K. (2010). Nursing informatics and the foundation of knowledge (2nd. ed.). Burlington, MA: Jones \& Bartlett Learning.

Melnyk, B., \& Fineout-Overholt, E. (2011). Making the case for evidence-based practice and cultivating a spirit of inquiry. In B. Melnyk, \& Fineout-Overholt, E. (Ed.), Evidence-based practice in nursing \& healthcare: A guide to best practice (2nd. ed., pp. 3-24). Philadelphia: Wolters Kluwer-Lippincott Williams \& Wilkins.

Miller, L., Graves, R., Jones, B., \& Sievert, M. (2010). Beyond Google: Finding and evaluating web-based information for community-based nursing practice. International Journal of Nursing Education Scholarship, 7(1).

Milne, D., Krishnasamy, M., Johnston, L., \& Sanchia, A. (2007). Promoting evidencebased care through a clinical research fellowship progamme. Journal of Clinical Nursing, 16, 1629-1639.

Morgan, D. (1998). Planning focus groups: Focus Group Kit 2. Thousand Oaks, CA: Sage Publications.

Newhouse, R., Dearholt, S., Poe, S., Pugh, L., \& White, K. (2007). Johns Hopkins nursing evidence-based practice model and guidelines. Indianapolis, IN: Sigma Theta Tau International.

Nicholson, L., Warde, C., \& Boker, J. (2007). Faculty training in evidence-based medicine: Improving evidence aquisition and critical appraisal. Journal of Education in the Health Professions, 27(1), 28-33.

Nolan, P. (2008). Evidence-based practice: Implications and concerns. Journal of Nursing Management, 16, 388-393.

Parkes, J., Hyde, C., Deeks, J, \& Milne, R. (2001). Teaching criticial appraisal skills in health care settings. Cochrane Database of Systematic Reviews 2001, Issue 3. Art. No.: CD001270.

Patton, M. (2002). Qualitative research \& evaluation methods (3rd ed.). Thousand Oaks, CA: Sage Publications.

Pearcey, P. (1995). Acheiving research-based nursing practice. Journal of Advanced Nursing, 22, 33-39. 
Phillips, J., Heitschmidt, M., Joyce, M., Staneva, I., Zemansky, P., Francisco, M., . . . Kranzer, S. (2006). Where's the evidence: An innovative approach to teaching staff about evidence-based practice. Journal for Nurses in Staff Development, 22(6), 296-301.

Pravikoff, D. S., Tanner, A.B, \& Pierce, S. T. (2005). Readiness of U.S. nurses for evidence-based practice. American Journal of Nursing, 105(9), 40-51.

Rosenfeld, P., Salazar-Riera, N., \& Vieira, D. (2002). Piloting an information literacy program for staff nurses. CIN: Computers, Informatics, Nursing, 20(6), 236-241.

Russell, C. L. (2009). Other sources of evidence. In N. Schmidt, \& Brown, J. (Ed.), Evidence-based pracitce for nurses: Appraisal and application of research (pp. 235-249). Sudbury, MA: Jones and Bartlett Publishers.

Rycroft-Malone, J., Seers, K., Titchen, A., Harvey, G., Kitson, A., \& McCormack, B. (2004). What counts as evidence in evidence-based practice? Journal of Advanced Nursing, 47(1), 81-90.

Sackett, D., Rosenberg, W., \& Gray, J. (1996). Evidence-based medicine; What it is and what it isn't. British Medical Journal, 312, 71-72.

Saranto, K., \& Hovenga, E. (2004). Information literacy-what is it about? Literature review of the concept and the context. International Journal of Medical Informatics, 73, 503-519.

Scott, S., \& Pollock, C. (2008). The role of nursing unit culture in shaping research utilization behaviors. Research in Nursing \& Health, 31, 298-309.

Shorten, A., Wallace, M., \& Crookes, P. (2001). Developing information literacy: A key to evidenced-based nursing. International Nursing Review, 48, 86-92.

Staggers, N., \& Thompson, C. (2002). The evolution of definitions for nursing informatics: A critical analysis and revised definition. Journal of the American Informatics Association, 9, 255-261.

Stevens, K. (2007). Critically appraising knowledge for clinical decision making. In B. Melnyk, \& Fineout-Overholt, E. (Ed.), Evidence-based practice in nursing \& healthcare (pp. 73-78). Philadelphia: Lippincott Williams \& Wilkins.

Stewart, D., \& Shamdasani, P. (1990). Focus groups: Theory and practice. Newbury Park, CA: Sage Publications.

Tannery, N., Wessell, C., Epstein, B., \& Gadd, C. (2007). Hospital nurses' use of knowledge-based information resources. Nursing Outlook, 55, 15-19. 
Taylor-Seehafer, M., Abel, E., Tyler, D., \& Sonstein, F. C. (2004). Integrating evidencebased practice in nurse practitioner education. Journal of the American Academy of Nurse Practitioners, 16(12), 520-525.

Thompson, C., Cullum, N., McCaughan, D., Sheldon, T., \& Ranor, P. (2004). Nurses, information use, and clinical decision making-the real world potential for evidence-based decisions in nursing. Evidence Based Nursing, 7, 68-72.

Thorne, S. (2008). Interpretive description. Walnut Creek, CA: Left Coast Press.

Thorne, S., Kirkham, S., \& O'Flynn-Magee, K. (2004). The analytic challenge in interpretive description. International Journal of Qualitative Methods, 3(1), 1-21.

Thorne, S., Kirkham, S., \& MacDonald-Emes, J. (1997). Interpretive description: A noncategorial qualitative alternative for developing nursing knowledge. Research in Nursing \& Health, 20, 169-177.

Usher, W. (2009). General practitioners' understanding pertaining to reliability, interactive and usability components associated with health websites. Behaviour \& Information Technology, 28(1), 39-44.

Verhey, M. (1999). Information literacy in an undergraduate nursing curriculum: Development, implementation, and evaluation. Journal of Nursing Education, 38, 252-259.

Verhey, M., Levy, J., \& Schmidt, R. (1998). Information RN. Glendale, CA: Cinahl Information Systems.

Verhoeven, F., Steehouder, M., Hendrix, R., \& van Gemert-Pijnen, E. (2009). How nurses seek and evaluate clinical guidelines on the Internet. Journal of Advanced Nursing, 66(1), 114-127.

Wallace, M., Shorten, A., Crookes, P, McGurk, C., \& Brewer, C. (1999). Integrating information literacies into an undergraduate nursing programme. Nurse Education Today, 19, 136-141.

White, R., \& Taylor, S. (2002). Nursing practice should be informed by the best available evidence, but should all first-level nurses be competent at research appraisal and utilization? Nurse Education Today, 22, 220-224.

Young, K. (2000). Informatics for healthcare professionals. Philadelphia: F. A. Davis Company. 


\section{APPENDIX A. RECRUITMENT FLYER}

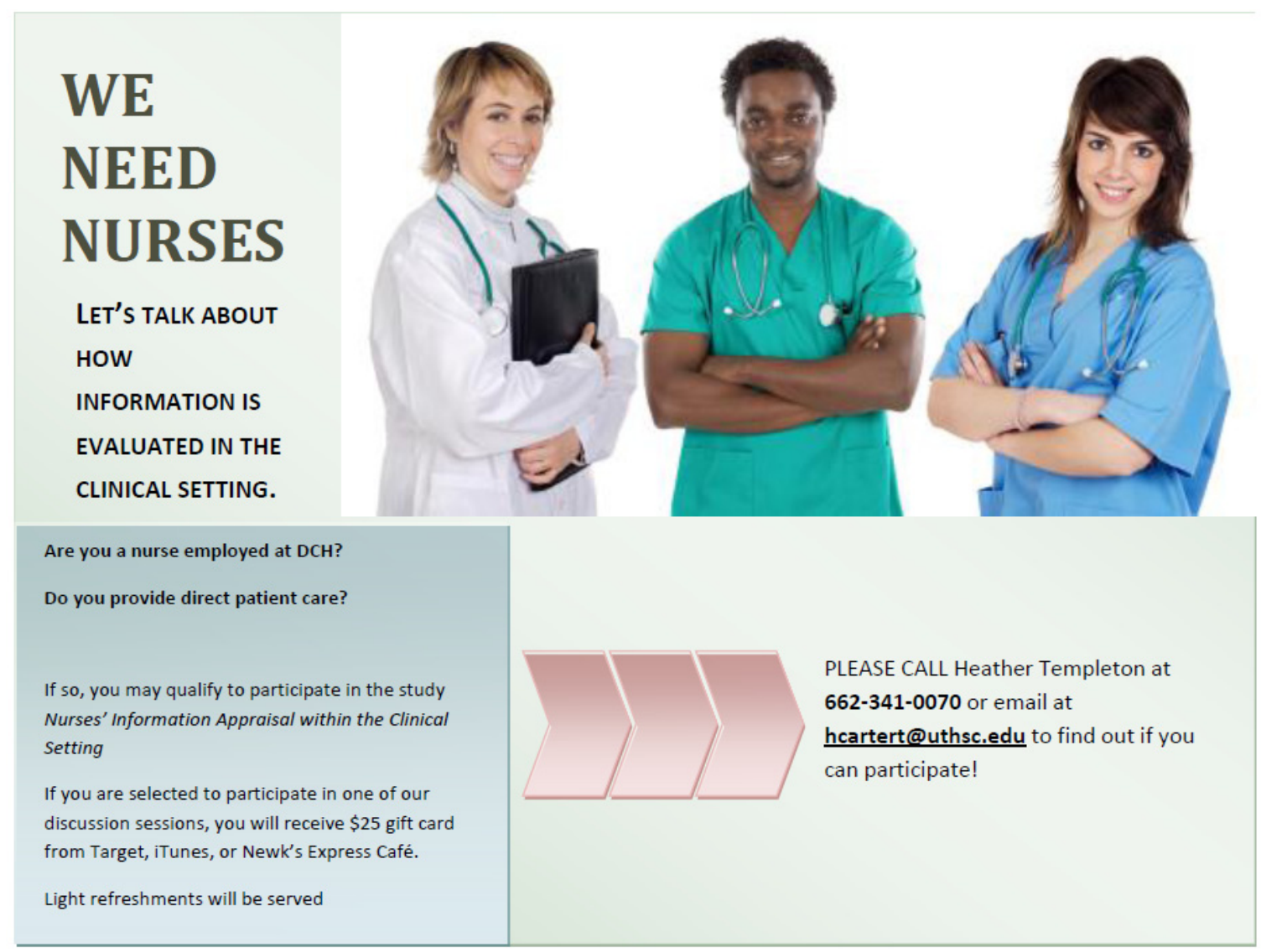




\section{APPENDIX B. NURSES' INFORMATION APPRAISAL WITHIN THE CLINICAL SETTINGS DEMOGRAPHICS SURVEY}

Date Focus Group \#

Instructions: Please complete the following questions. Please use an " $X$ " to designate your responses. Be sure that your responses are legible and your response is clearly marked.

1. What is your gender? Select one.

Male

Female

2. What year were you born?

19

3. What year were you originally licensed as a nurse?

(report as a four digit format)

4. Which initial educational program qualified you to sit for the RN licensure exam? Select ONLY ONE.

Diploma Program

Associate Degree

Bachelor's Degree

Master's Degree

Doctorate (N.D.)

TURN TO THE NEXT PAGE 
5. Are you currently enrolled in a formal education program leading to an academic degree or certificate? Select one.

Yes
No*

*If no, skip to question number 8

6. Is this a formal education program? Select one.

In nursing

In a non-nursing field

7. What type of degree/award are you currently working toward? Select one.

Associate Degree
Bachelor's Degree
Master's Degree
Doctoral Degree
Certificate

TURN TO THE NEXT PAGE 
8. Which of the following academic degrees have you earned? Select all that apply.

Associate degree in nursing

Associate degree in another field

Bachelor's degree in nursing

Bachelor's degree in another field

Master's degree in nursing

Additional Master's in nursing

Master's degree in another field

Doctorate in nursing

Doctorate in another field

Not Applicable

9. Have you ever had graduate nursing education in the following areas? Select all that apply.

Clinical Nurse Specialist (CNS)

Nurse Anesthetist (NA)

Nurse-midwife (NM)

Nurse Practitioner (NP)

Clinical Nurse Leader (CNL)

None of the above

TURN TO THE NEXT PAGE 
10. In what type of area do you spend the majority of your time in during a typical work week? Select ONLY ONE.

\begin{tabular}{|c|c|c|}
\hline & Administration & Operating room \\
\hline & Community Health/Public & Outpatient department \\
\hline \multicolumn{3}{|c|}{$\overline{\text { Health }}$} \\
\hline & & Perioperative unit \\
\hline & & Psychiatric/Mental Health \\
\hline & Education & \\
\hline & Emergency Department & $\begin{array}{l}\text { Radiologic (diagnostic or } \\
\text { therapeutic) }\end{array}$ \\
\hline & General/specialty inpatient unit & Spinal Cord \\
\hline & $\begin{array}{l}\text { (other than critical care or step- } \\
\text { down) }\end{array}$ & Injury/Rehabilitation \\
\hline & Home health care & $\begin{array}{l}\text { Step-down, transitional, } \\
\text { progressive, telemetry unit }\end{array}$ \\
\hline & Hospice unit & Multiple units, none over $50 \%$ \\
\hline & Informatics & Other specific area, specify: \\
\hline & Labor/delivery roo & \\
\hline
\end{tabular}

Thank you for completing this questionnaire. Please return this completed questionnaire to one of the focus group leaders. If there are questions about your responses, a focus group leader will check with you prior to the end of this focus group. 


\section{APPENDIX C. SEMI-STRUCTURED FOCUS GROUP INTERVIEW}

\section{Semi-Structured Focus Group Interview Guide}

1. Opening Question: Tell us your first name, how long you have been at $\mathrm{DCH}$, and an example of your favorite type of patient care assignment.

2. What comes to mind when you hear the term "information evaluation"?

3. Transition: Think back to a time when you were caring for a patient (or patients) and you had questions and needed more information to care for them. Describe this situation on the note card provided.

Note card will ask the following questions:

- What type of question did you have?

- What type of unit you were working on?

- What was the patient's diagnosis or what type of patients were you working with?

$\rightarrow$ Prompt:

LIST OF EXAMPLE SITUATIONS

Drug/medication questions

Disease process questions

Questions about patient symptoms

Disease management/treatment questions

Clinical practice guideline questions

Patient education/health promotion needs

Planning appropriate care (culture, age, environment)

Tradition versus evidence questions

Care delivery/coordination questions

Quality improvement questions 
4. Intermediate Transition: Tell us about the situation you described on your note card.

5. Transition: How did you get the additional information you needed to care for your patient (or patients)?

6. Transition: What type(s) of information resources did you use?

$\rightarrow$ Prompt:

Where did you go for the information resource?

In what format did you find the resource?

LIST OF COMMON INFORMATION RESOURCES

Ask colleagues or peers

Search bibliographic databases (PubMed, CINAHL)

Search the Internet/World Wide Web

Hospital Intranet

Read journals, books, or other print materials

Other (specify)

7. Key: What was it about this (or these) resource(s) that made you trust it?

$\rightarrow$ Prompt:

What made you comfortable using this (or these) resource(s)?

8. Key: What rules, guidelines, or principles do you use to help you evaluate information when you are in the clinical setting?

9. Key: How often do you find yourself evaluating information resources in the clinical setting to determine if it is reliable? 
10. Moderator Synopsis of the discussion followed by a question to the group: Can you help me clarify my thoughts to make sure I have heard your discussion correctly?

11. Closing: Has your definition of information evaluation changed after our focus group discussions?

$\rightarrow$ Follow-up question, asked if at least one person in the group indicates her/his definition has changed: If so, how has it changed? 


\title{
APPENDIX D. DEBRIEFING CHECKLIST
}

\author{
Debriefing Checklist
}

Are changes in the questioning route needed? If so, what changes are necessary?

What were the participant characteristics?

What descriptive phases or words were used by participants as they discussed key questions?

Were there any themes noted in responses to the key questions?

Were there subthemes indicating a point of view by participants with common characteristics?

Were participants enthusiastic?

Were there consistencies between participants' comments and their reported behaviors?

Was there any body language worth noting?

Are there new avenues of questioning that should be considered in future focus groups?

Are their questions that need to be eliminated, revised, or added?

What was the overall mood of the discussion? 


\title{
APPENDIX E. FOCUS GROUP PARTICIPANT CONSENT FORM
}

\author{
Nurses' Information Appraisal within the Clinical Setting \\ Focus Group Participant Consent Form
}

You are being given the opportunity to participate in this research study. You do not have to take part in this study. Your refusal to participate will involve no penalty or loss of rights to which you are otherwise entitled. You are free to later withdraw your consent and discontinue your participation in this study at any time.

You are consenting to participate in a research study involving DCH nurses. The purpose of this study is to describe the process of evaluating information within the clinical setting. Research questions addressed in this study include: 1) What is information appraisal in the clinical setting? and 2) How do nurses perform information appraisal in the clinical setting?

Your signature below acknowledges the following:

$\checkmark \quad$ This focus group meeting is part of a research study.

$\checkmark$ Today's focus group session will last 1 to 1.5 hours.

$\checkmark$ You will only be participating in 1 focus group.

$\checkmark \quad$ The discussion will be audio recorded for the purpose of capturing important details

$\checkmark \quad$ Your identity will be kept confidential.

$\checkmark \quad$ Risks associated with the study include uncomfortable or troublesome feelings or emotions when completing the questionnaire or focus group questions, however, you may choose not to answer any questions at any time. Additionally, there is a potential risk of loss of confidentiality as audio recordings are transcribed. Every effort will be made to keep your information confidential, however, this cannot be guaranteed.

$\checkmark$ You will not be identified in any presentations or publications based on the results of this research study.

$\checkmark$ You may choose not to answer any questions at any time during the focus group.

$\checkmark$ General benefits of the study include advancement in the understanding of information evaluation within the nursing discipline.

$\checkmark \quad$ This is a qualitative study for which there are no alternatives.

$\checkmark$ You will receive a $\$ 25$ gift card once the focus group meeting is adjourned.

$\checkmark$ You agree not to talk about our discussions with others outside of your focus group.

Questions:

Please feel free to contact the principal investigator, Heather Templeton, with questions or concerns about this study. You may call at any time at the numbers listed below:

Heather Templeton, Principal Investigator

662-323-6686 (day/evening)

662-341-0070 (cell)

You may contact Terrence F. Ackerman, Ph.D., UTHSC IRB Chairman at 901-448-4824 or visit the IRB website at http://www.uthsc.edu/research/research_compliance/IRB/participant complaint.php if you have any questions about your rights as a participant in this study or your rights as a research subject.

As a participant you will receive a copy of this consent form.

Signature of Focus Group Participant Date Date 


\section{APPENDIX F. INSTITUTUTIONAL REVIEW BOARD APPROVAL LETTERS}

\begin{tabular}{lr}
\hline THE UNIVERSITY OF TENNESSEE \\
Health Science Center \\
\hline \\
Institutional Review Board \\
910 Madison Avenue, Suite 600 \\
Memphis, TN 38163 \\
Tel: (901) 448-4824
\end{tabular}

December 20, 2010

Heather D Carter-Templeton, MSN

College of Nursing

Department of Nursing

2581 W. Lakeshore Dr.

Starkville, MS

Re: 10-01 135-XP: Nurses' Information Appraisal within the Clinical Setting

Dear Ms. Carter-Templeton,

The Administrative Section of the UTHSC Institutional Review Board (IRB) reviewed your application for the above referenced project. It determined that your application is eligible for expedited review under category (7). It is approved with alteration of the informed consent disclosure under 45CFR46.116 (d). The alteration consists in the use of a consent cover statement for the survey in lieu of an informed consent interview. This alteration is permissible because the research involves no more than minimal risk, does not adversely affect the rights and welfare of subjects, and could not be practicably carried out without the alteration. Condition (4) is not applicable. Documentation of informed consent is also waived under 45CFR46.117(c)(2), in that the research involves no more than minimal risk and does not involve procedures for which written consent is normally required outside the research context. Documentation of consent will consist in the willingness of subjects to complete the survey. The IRB has reviewed these materials and determined that they do comply with proper consideration for the rights and welfare of human subjects and the regulatory requirements for the protection of human subjects. Therefore, this letter constitutes full approval by the IRB of your application, questionnaires/surveys [Semi-Structured Focus Group Interview Guide; Demographic Survey]; recruitment flyer and consent cover statement dated December 3, 2010 [stamped IRB approved on December 20, 2010]. This study was approved for 12 months with an expiration date of December 20,2011.

In the event that subjects are to be recruited using solicitation materials, such as brochures, posters, webbased advertisements, etc., these materials must receive prior approval of the IRB. Any revisions in the approved application must also be submitted to and approved by the IRB prior to implementation. In addition, you are responsible for reporting any unanticipated serious adverse events or other problems involving risks to subjects or others in the manner required by the local IRB policy.

Finally, re-approval of your project is required by the IRB in accord with the conditions specified above. You may not continue the research study beyond the time or other limits specified unless you obtain prior written approval of the IRB.

Sincerely,

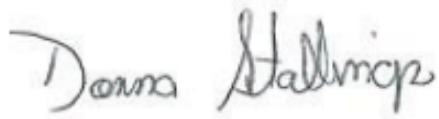

Signature applied by Donna L Stallings on 12/20/2010 06:54:24 AM CST

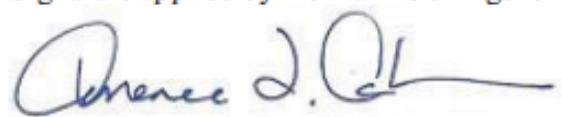

Signature applied by Terrence F Ackerman on 12/20/2010 06:55:01 AM CST 


\section{DCFH.}

Date: January 18,2011
BRYAN N. KINDRED, FACHE

President/CEO

809 University Blvd. E. Tuscaloosa, AL 35401

205.759 .7111

\section{Institutional Review Board \\ FWA \#00006291 \\ REVIEW OUTCOME}

Name of Study: "Nurses' Information Appraisal within the Clinical Setting"

Principal Investigator: Heather Carter-Templeton, MSN, RN

Items(s) for Review: Application for Expedited Review and related materials; request for waiver of application fee

\section{Review Outcome: Approved}

\section{Approval Expiration: January 18, 2012}

Comments: It is expected that the study staff will work closely with other DCH staff as necessary to ensure the welfare of participants. Principal investigators and any co-investigators are expected to keep appropriate records concerning the study. Furthermore as a condition of this approval, the Institutional Review Board must be notified of any complications or unanticipated circumstances encountered. Study amendments are not to be implemented without prior IRB approval except when necessary to eliminate apparent immediate hazards to human subjects. The IRB should be notified upon completion of the study and a copy of the final results provided.

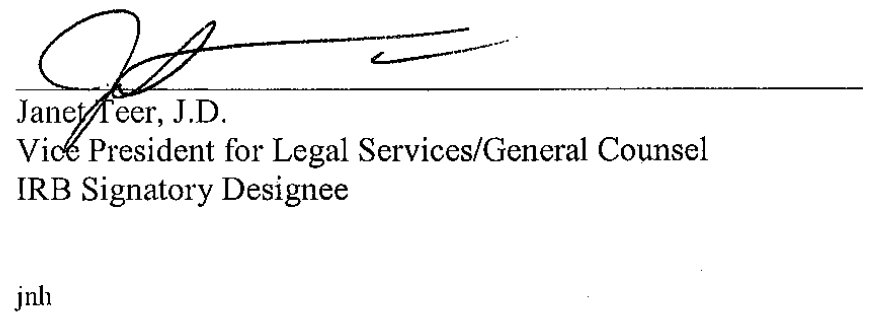


January 21,2011

Office for Research Institutional Review Board for the Protection of Human Subjects

THE UNIVERSITY OF ALABAMA

R E S E A R C H

Heather Carter-Templeton, RN, MSN

Capstone College of Nursing

The University of Alabama

Box 870358

Re: IRB \# 11-OR-018 "Nurses' Information Appraisal within the Clinical Setting"

Dear Ms. Carter-Templeton:

The University of Alabama Institutional Review Board has granted approval for your proposed research

Your application has been given expedited approval according to 45 CFR part 46. Approval has been given under expedited review category 7 as outlined below:

(7) Research on individual or group characteristics or behavior (including, but not limited to, research on perception, cognition, motivation, identity, language, communication, cultural beliefs or practices, and social behavior) or research employing survey, interview, oral history, focus group, program evaluation, human factors evaluation, or quality assurance methodologies.

Your application will expire on January 20,2012. If your research will continue beyond this date, complete the relevant portions of Continuing Review and Closure From. If you wish to modify the application, complete the Modification of an Approved Protocol Form. When the study closes, complete the appropriate portions of FORM: Continuing Review and Closure.

Please use reproductions of the IRB approved informed consent form to obtain consent from your participants.

Should you need to submit any further correspondence regarding this proposal, please include the above application number.

Good luck with your research.

Sincerely,

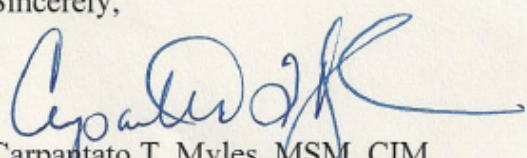

Carpaptato T. Myles, MSM, CIM

Director \& Research Compliance Officer

Office for Research Compliance

The University of Alabama 


\begin{tabular}{lr}
\hline THE UNIVERSITY OF TENNESSEE \\
Health Science Center \\
\hline \\
Institutional Review Board \\
910 Madison Avenue, Suite 600 \\
Memphis, TN 38163 \\
Tel: (901) 448-4824
\end{tabular}

February 21, 2011

Heather Carter-Templeton, MSN, RN

College of Nursing

Department of Nursing

Lamar Alexander Building

Re: 10-01135-XP

Study Title: Nurses' Information Appraisal within the Clinical Setting

Dear Ms. Carter-Templeton,

The Administrative Section of the UTHSC Institutional Review Board (IRB) reviewed your application for revision of your previously approved project, referenced above. It determined that your application is eligible for expedited review under 45 CFR 46.110(b) (2). The attached revisions were approved as complying with proper consideration of the rights and welfare of human subjects and the regulatory requirements for the protection of human subjects. Approval does not alter the expiration date of this project, which is December 20, 2011.

The revisions to this study may not be instituted until you receive approval from the institution(s) where the research is being conducted.

In the event that subjects are to be recruited using solicitation materials, such as brochures, posters, webbased advertisements, etc., these materials must receive prior approval of the IRB. Any revisions in the approved application must also be submitted to and approved by the IRB prior to implementation. In addition, you are responsible for reporting any unanticipated serious adverse events or other problems involving risks to subjects or others in the manner required by the local IRB policy.

Finally, re-approval of your project is required by the IRB in accord with the conditions specified above. You may not continue the research study beyond the time or other limits specified unless you obtain prior written approval of the IRB.

Sincerely,

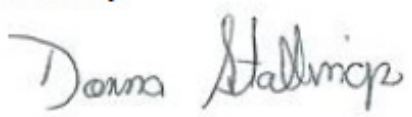

Signature applied by Donna L Stallings on 02/21/2011 11:14:05 AM CST

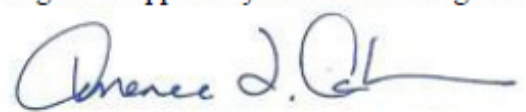

Signature applied by Terrence F Ackerman on 02/21/2011 11:15:49 AM CST

Donna Stallings, CIM

IRB Administrator

UTHSC IRB
Terrence F. Ackerman, Ph.D.

Chairman

UTHSC IRB 


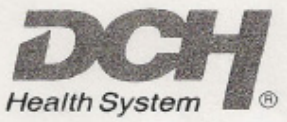

809 University Blvd. E.

Tuscaloosa, AL 35401

205.759.7111

\section{Institutional Review Board \\ FWA \# 00006291}

\section{REVIEW OUTCOME}

Name of Study: "Nurses' Information Appraisal within the Clinical Setting"

Principal Investigator: Heather-Carter-Templeton, MSN, RN

Date Reviewed: January 31,2011

Review Outcome: Approved

Approval Expiration: February 21, 2011

Comments: Temporary approval has been granted for the revision to the consent form for the above named study to include Ms. Tanta Myles as requested and approved by the University of Alabama IRB. This approval is effective until the February 21, 2011, regularly scheduled meeting of the DCH Health System IRB.

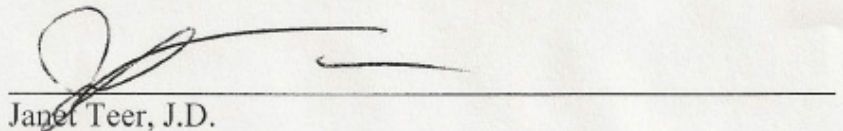

Vice President for Legal Services/General Counsel

IRB Signatory Designee

mdc 


\section{VITA}

Heather D. Carter-Templeton was born in Huntington, West Virginia in 1974. She graduated South Charleston High School in South Charleston, WV in 1992. Heather received her ADN from Southern Union State Community College in Opelika, AL in 1995, her BSN from the University of Alabama in Huntsville, AL in 1999, and her MSN with a concentration in Health Systems Management from Vanderbilt University in Nashville, TN in 2000. In 2006 Heather was accepted into the nursing Ph.D. program at The University of Tennessee Health Science Center (UTHSC). Heather's professional nursing background is diverse. She began her nursing career as a staff nurse at East Alabama Medical Center in Opelika, AL. She has worked in a variety of patient care settings, including medical-surgical, critical care, post-op anesthesia, and management. Other professional positions held include Project Coordinator for the HRSA funded LISTEN Project at the University of Tennessee Health Science Center (UTHSC), Nursing Instructor at the Mississippi University for Women (MUW) and Research Nurse at Vanderbilt University. She is currently a Nursing Instructor at the University Of Alabama Capstone College Of Nursing. As a doctoral student at UTHSC, Heather conducts research in the areas of information literacy and healthcare information technology. The purpose of her qualitative study is to describe the process of information appraisal in the clinical setting. Her doctoral preparation has also included directed studies in the areas of decision support systems, program evaluation and focus group methodology. Heather will graduate with a Doctor of Philosophy with a major in Nursing in December 2011. 